\title{
L'IMAGINAIRE ÉTHIOPIEN DANS LE PREMIER MONDE HISPANIQUE : ESCLAVAGE ET BAPTÊME DANS LE CATÉCHISME ÉVANGÉLIQUE DE SANDOVAL
}

$\underline{\text { Chloe L. Ireton, Traduit de l'anglais (États-Unis) par Élise Trogrlic }}$

Belin | « Revue d’histoire moderne \& contemporaine »

2021/2 n 68-2 | pages 104 à 130

ISSN 0048-8003

ISBN 9782410022759

DOI 10.3917/rhmc.682.0104

Article disponible en ligne à l'adresse :

https://www.cairn.info/revue-d-histoire-moderne-etcontemporaine-2021-2-page-104.htm

Distribution électronique Cairn.info pour Belin.

(C) Belin. Tous droits réservés pour tous pays.

La reproduction ou représentation de cet article, notamment par photocopie, n'est autorisée que dans les limites des conditions générales d'utilisation du site ou, le cas échéant, des conditions générales de la licence souscrite par votre établissement. Toute autre reproduction ou représentation, en tout ou partie, sous quelque forme et de quelque manière que ce soit, est interdite sauf accord préalable et écrit de l'éditeur, en dehors des cas prévus par la législation en vigueur en France. Il est précisé que son stockage dans une base de données est également interdit. 


\section{L'imaginaire éthiopien dans le premier monde hispanique: esclavage et baptême dans le Catéchisme évangélique de Sandoval}

Chloe L. IRETON

Au début du XVII ${ }^{\mathrm{e}}$ siècle ${ }^{1}$, Carthagène des Indes (dans l'actuelle Colombie) est le plus important port de commerce d'esclaves de l'Atlantique hispanique ${ }^{2}$. Établi à Carthagène, le prêtre jésuite Alonso de Sandoval (1576-1652) était particulièrement préoccupé par le nombre des baptêmes illicites que les prêtres et les marchands d'esclaves administraient aux Africains réduits en esclavage dans les ports de traite en Angola, au Cap-Vert et en Guinée, ainsi que sur les navires négriers à destination des Indes espagnoles. Il consacra sa vie missionnaire et intellectuelle à corriger cet usage illégitime du sacrement. Sandoval et ses disciples veillaient quotidiennement sur l'âme des Africains qui avaient survécu à la brutalité sans nom de leur arrachement à l'Afrique, enchaînés sous le pont des négriers pour débarquer dans le port de Carthagène ${ }^{3}$. Plus généralement, Sandoval organisa également une campagne, fondée sur un réseau de correspondances transatlantique, visant à inciter les autorités du monde ibérique à

1. Je remercie Adriana Urrea et Roberto Burgos Cantor d'avoir si généreusement pensé avec moi l'histoire des jésuites de Carthagène au début du XVII siècle. J'ai une pensée émue pour le maestro Roberto Burgos Cantor, décédé avant que je puisse partager le fruit de ce travail avec lui. Je tiens à remercier aussi Herman L. Bennett, Trevor Burnard, Carlos Cañete Castañeda, Jorge Cañizares-Esguerra, Susan Deeds, Rafael García Castañeda, Andrea Guerrero Mosquera, Emiro Martínez-Osorio, Ernesto Mercado Montero, Adrian Masters, Stuart Mcmanus, Raffaele Moro, Santiago Muñoz Arbelaez, Erin K. Rowe et Evelyn K. Welch pour leurs précieux commentaires sur les premières versions de ce manuscrit et la pertinence de leurs remarques critiques. Pour leur lecture attentive des premières versions de cet article, je remercie les participants des ateliers organisés à l'Université de los Andes de Bogotá et l'Escuela de Estudios Antropológicos. J'ai bénéficié d'une résidence à la John Carter Brown Library qui m’a permis de faire des recherches cruciales pour la rédaction de cet article.

2. Alex Borucki, David Eltis, David Wheat, «Atlantic History and the Slave Trade to Spanish America", The American Historical Review, 120-2, 2015, p. 433-461. D. WHEAT, "The First Great Waves: African Provenance Zones for the Transatlantic Slave Trade to Cartagena De Indias, 15701640 ", The Fournal of African History, 52-1, 2011, p. 1-22.

3. Sanctissimo ac Beatissimo Domino Nostro, Domino Clementi Divina Provida. Papae Decimo, salutem et apostolicam dilectionem [manuscrit], 1676, Biblioteca Nacional de Colombia, RM 281; Proceso de beatificación y canonización de san Pedro Claver, Bogota, Pontifical Universidad Javeriana, 2002, "Administración del Bautismo», p. 84-124. 
rebaptiser les sujets coloniaux noirs, libres ou encore esclaves. Cette campagne visant à assurer un véritable baptême aux Africains noirs et à leurs descendants culmina avec la rédaction du traité Naturaleza, policia sagrada i profana, costumbres $i$ ritos, disciplina $i$ catechismo evangelico de todos Etiopes (1627), revu et republié sous le titre Tomo Primero de Instauranda Athiopum Salute; Historia De Athiopia, naturaleça, Policia Sagrada y Profana, Costumbres, ritos, y Cathecismo Evangelico, de todos les Athiopes (1647) ${ }^{4}$. Sandoval développa en outre une justification théologique de l'asservissement des Africains noirs et de leur déplacement forcé vers les Antilles espagnoles. Le raisonnement théologique de Sandoval pour justifier cet asservissement et ses inquiétudes quant au baptême des Africains sont deux facettes du même argumentaire théologique, fondé sur la restauration d'une Église éthiopienne ancestrale dans les Amériques. L'argumentation développée par Sandoval offre ainsi une perspective unique sur un ensemble extrêmement riche de discours sur l'Afrique, la couleur noire et la notion de salut dans le monde ibérique du XVII ${ }^{\mathrm{e}}$ siècle.

Pour comprendre la pluralité de ces discours, il est essentiel de revenir sur la manière dont s'est développé un paysage imaginaire de l'Éthiopie au XVI ${ }^{\mathrm{e}}$ et au début du XVII ${ }^{\text {e }}$ siècle. Dans certains cercles, l'Éthiopie est un lieu de discours divergents sur la signification de la couleur noire, la justification de l'esclavage et la guerre juste en Afrique, ainsi que sur la relation entre couleur de peau et lignée religieuse. $\mathrm{Au} \mathrm{XVI}$ et au début du XVII ${ }^{\mathrm{e}}$ siècle, les théologiens ibériques produisent des histoires composites et contrastées de la chrétienté éthiopienne, présentant souvent les Africains comme les premiers chrétiens. Pour les religieux missionnaires, l'Éthiopie chrétienne fait l'objet de débats passionnés: certains auteurs utilisent l'histoire de la chrétienté éthiopienne pour justifier l'asservissement des Africains noirs, tandis que d'autres se servent de l'histoire ancienne de la religion chrétienne pour élaborer une critique très ferme de l'esclavage lui-même. Les lettrés du monde ibérique d'origine africaine tels que l'intellectuel Juan Latino (Baena?/Éthiopie?, 1518 - Grenade, 1596), établi à Grenade, échafaudent un récit de l'héritage chrétien de l'Éthiopie qui met les Éthiopiens sur un pied d'égalité

4. Alonso de SANDOVAL, Naturaleza, policia sagrada i profana, costumbres i ritos, disciplina i catechismo evangelico de todos Etiopes, por el P. Alonso de Sandoval... Sevilla, F. de Lira impresor, 1627 (BnF Paris, Réserve des livres rares, 4-O3C-6., disponible en ligne: https://gallica.bnf.fr/ark:/12148/bpt6k73763z). ID., Tomo primero De instauranda aethiopum salute: Historia de Aethiopia, naturaleça, policia sagrada y profana, costumbres, ritos y cathecismo evangelico de todos los aethiopes.... dividida en dos tomos..., por Alonso de Paredes en Madrid, 1647 (Biblioteca Histórica de la Universidad Complutense de Madrid, Biblioteca digital Dioscórides). Voir aussi les deux transcriptions publiées de la version de 1627 : Alonso DE SANDOVAL, De Instauranda Aethiopum Salute: El mundo de la esclavitud negra en América, Angel VALTIERRA (éd.), Bogotá, Empresa Nacional de Publicaciones, 1956, et Alonso DE SANDOVAL, Un tratado sobre la esclavitud. De Instauranda Aethiopum Salute, Enriqueta VILA Vilar (éd.), Madrid, Alianza Editorial, 1987. Pour une discussion de ces éditions, voir Luz Adriana MAYA, De Instauranda Aethiopum Salute: un apport documentaire à l'histoire africaines et afroaméricaine, Paris, mémoire, Université de Paris I-PanthéonSorbonne - Centre de recherches africaines, 1989; Eduardo RESTREPO, «De Instauranda Æthiopum Salute: Sobre las ediciones y características de la obra de Alonso de Sandoval", Tabula Rasa. Revista de Humanidades del Colegio Mayor de Cundinamarca, 3, 2005, p. 13-26; "Introducción", in Enriqueta VILA VILAR (éd.), Un tratado sobre la esclavitud..., op. cit., p. 15-44. 
avec les Castillans et ébauchent un abolitionnisme timide sur la base des origines chrétiennes des Noirs d'Afrique ${ }^{5}$. Ce faisant, Latino oriente de manière cruciale les débats sur la chrétienté africaine ainsi que sur le lien entre couleur de peau et héritage religieux ${ }^{6}$. Son discours s'épanouit à Carthagène des Indes au début du XVII ${ }^{\mathrm{e}}$ siècle chez Alonso de Sandoval, qui promeut la vision idyllique d'une Éthiopie chrétienne où la noirceur de la peau est lue comme symbole d'un christianisme ancien et pur, celui d'une Église primitive directement élue par Dieu. Mais, à l'inverse des perspectives anti-esclavagistes de Latino, Sandoval se sert de l'histoire de l'Église chrétienne en Éthiopie pour légitimer l'asservissement de tous les Africains noirs, dans le but de vider l'Afrique de sa population pour rétablir une Église noire élue aux Antilles espagnoles. La diffusion de cette pensée auprès d'une poignée de prêtres jésuites des Caraïbes au début du XVII ${ }^{\mathrm{e}}$ siècle offre un éclairage particulièrement instructif sur les discours ibériques sur la couleur de peau, la pureté du sang, la justification de l'esclavage, la chrétienté africaine et le baptême.

\section{SANDOVAL DANS LES DÉbATS HISTORIOGRAPHIQUES SUR LA COULEUR NOIRE ET LA RACE}

L'utilisation par Alonso de Sandoval de l'Éthiopie comme instrument théologique au service de la justification de l'esclavage est passée largement inaperçue au sein du corpus très large de travaux portant sur la vision de l'Afrique et des Africains chez les Jésuites. Pour Jean-Pierre Tardieu, le recours par Sandoval à l'Éthiopie antique et à des figures chéries de l'Église éthiopienne constitue un simple outil rhétorique visant à distraire ses lecteurs ${ }^{7}$. Certains chercheurs ont analysé son utilisation du concept de guerre juste et de la logique aristotélicienne dans le cadre de la justification de la traite des Africains; ils se sont également intéressés aux discours relayés par Sandoval sur la pureté du sang, ainsi qu'à sa construction discursive de la différence. Cependant, tous restent muets sur les interprétations théologiques de l'Éthiopie chez Sandoval ${ }^{8}$. Par ailleurs, Margaret Olsen et Hélène

5. Juan Latino, De augusta et catholica regalium corporum translatione per Catholicum Phillipum [...]. Epigrammatum sive Epitaphiorum, libri duo, Grenade, Hugo Mena, c. 1576, et "Elegy for Phillip II, "On the Birth of Untroubled Times" ", in Elizabeth R. WRIGHT, The Epic of Juan Latino. Dilemmas of Race and Religion in Renaissance Spain, Toronto, University of Toronto Press, 2016, p. 22-23 ainsi que Appendice 1, p. 185-190. ID., The Song of Fohn of Austria, in Elizabeth R. WRIGHT, Sarah SPENCE, Andrew Lemons (éd.), The Battle of Lepanto, Cambridge, Harvard University Press, 2014, p. 288-405.

6. E. R. Wright, The Epic of Juan Latino..., op. cit.; Aurelia MARTín CASAREs, Fuan Latino. Talento Y Destino. Un Afroespañol En Tiempos De Carlos V Y Felipe II, Grenade, Universidad de Granada, 2016; Baltasar FrA-Molinero, "Juan Latino and his racial difference», in T. F. EARLE, K. J. P. LowE (éd.), Black Africans in Renaissance Europe, Cambridge, Cambridge University Press, 2005, p. 326 344; E. R. WRIGHt, "Narrating the ineffable Lepanto: The Austrias Carmen of Joannes Latinus (Juan Latino)", Hispanic Review, 77-1, 2009, p. 71-92; Christopher MAURER, "Un monarca, un imperio y una espada: Juan Latino y el soneto de Hernando de Acuña sobre Lepanto", Hispanic Review, 61-1, 1993, p. 35-51. Juan Latino est également cité dans de nombreuses œuvres littéraires de la période, notamment Don Quichotte de Cervantes (1605) et La Dama Boba de Lope DE VEGA (1613).

7. Jean-Pierre TARDIEU, «Du bon usage de la monstruosité: la vision de l'Afrique chez Alonso de Sandoval (1627)", Bulletine Hispanique, 86-1/2, 1984, p. 172.

8. María Eugenia Chaves MaLdonado (éd.), Genealogias de la diferencia: tecnologias de la salvación y representación de los africanos esclavizados en Iberoamérica colonial, Bogotá, Editorial de la Pontificia 
Vignaux ont dépeint Sandoval comme un partisan timide de la lutte contre l'esclavage qui aurait exprimé des doutes non négligeables sur l'asservissement des Africains noirs ${ }^{9}$. Nicole von Germeten s'intéresse davantage au sens à donner à l'Éthiopie chez Sandoval dans l'introduction de sa traduction anglaise du traité:

"[L]'usage du terme "Éthiopie” pour désigner l'Afrique dans son ensemble voire, comme le fait Sandoval, tous les individus noirs de peau partout dans le monde, laisse penser que les Européens au XVI ${ }^{\mathrm{e}}$ et au XVII ${ }^{\mathrm{e}}$ siècle accordaient un statut particulier à l'Éthiopie, prise cette fois dans le sens de ses limites actuelles, comme une version idéalisée du royaume chrétien ${ }^{10}$.

D'autres chercheurs avancent l'idée que Sandoval utilise le terme «Éthiopiens» tout au long du texte comme une simple alternative lexicale au terme "Noirs»" Les chercheurs qui ont étudié la manière dont Sandoval présente des hagiographies de saints noirs éthiopiens ont accordé une importance plus grande à son utilisation de l'Éthiopie. Larissa Brewer-García a souligné que le rôle de l'Éthiopie chez Sandoval «et ses liens avec la noirceur biblique et chrétienne primitive» font partie de la tentative du jésuite de «dresser un portrait de la sainteté noire qui soit légitime tout en étant conforme à la position servile de la majorité des hommes et des femmes noirs vivant dans les sociétés coloniales». De son côté, Erin K. Rowe a affirmé que «Sandoval a créé une continuité temporelle de la sainteté éthiopienne allant des siècles bibliques à son époque, en passant par le Moyen Âge. Il établit ainsi la dignité et la faculté morale des "Éthiopiens", de l'Ancien Testament jusqu'à son temps" afin "d'attaquer ceux qui affirment que les Africains asservis n'ont pas la raison requise pour participer à la communauté chrétienne»12.

Universidad Javeriana, Instituto de Estudios Sociales y Culturales Pensar, Abya-Yala, 2009; Juliana Beatriz AlmEIDA DE SoUZA, "Las Casas, Alonso de Sandoval e a defesa da escravidão negra", TOPOI, 7-12, 2006, p. 37-47. Catalina Ariza MONTAÑEZ, «Los objetos con alma: La legitimidad de la esclavitud en el discurso de Aristóteles y Alonso de Sandoval (una aproximación desde la construcción del cuerpo)", Fronteras De La Historia, 10, 2005, p. 139-170.

9. Ma lecture de Sandoval comme défenseur de l'esclavage diverge de celle des chercheurs qui voient en lui un précurseur des anti-esclavagistes. Ainsi, Hélène Vigneux a suggéré que le jésuite présentait une vision critique ambivalente de la juste réduction en esclavage des Africains parce qu'une position anti-esclavagiste aurait été intenable à l'époque: elle aurait conduit à la marginalisation de Sandoval et à l'interdiction de la publication de son traité. Hélène VIGNAUX, L'Église et les Noirs dans l'audience du Nouveau Royaume de Grenade, Montpellier, Presses universitaires de la Méditerranée, 2009 (DOI: 10.4000/books.pulm.496), «2.3. La justification de l'esclavage et de la traite» et «2.3.2. La position d'Alonso de Sandoval", p. 64-88 en ligne (p. 33-83 dans la version imprimée). Voir également Margaret M. OLSEN, Slavery and Salvation in Colonial Cartagena de Indias, Gainesville, University Press of Florida, 2004.

10. Nicole Von Germeten, «Introduction», in SAndoval, Treatise on Slavery..., op. cit., p. XXII.

11. M. E. Chavez Maldonado (éd.), Genealogias de la diferencia..., op. cit. Pour une interprétation différente de la signification de l'Éthiopie chez Sandoval, voir Luz Adriana MAYA, "Memorias en conflicto y paz en Colombia: la discriminación hacia lo(s) "negro(s)" ", Estudios Latinoamericanos sobre cultura y transformaciones sociales en tiempos de globalización 2, Buenos Aires, Consejo Latinoamericano de Ciencias Sociales, 2001, p. 179-195; Eduardo RESTREPO, "El negro en un pensamiento colonial del siglo XVII: diferencia, jerarquía y sujeción sin racialización", in M. E. CHAVES MALDONADO (éd), Genealogia de la diferencia, op. cit., p. 118-176.

12. Larissa BREWER-GARCÍA, "Hierarchy and Holiness in the Earliest Colonial Black Hagiographies: Alonso de Sandoval and His Sources", The William and Mary Quarterly, 76-3, 2019, p. 477-508. Erin K. Rowe, Black Saints in Early Modern Global Catholicism, New York, Cambridge University Press, 2019. 
Le silence historiographique qui entoure les échanges initiés par Sandoval au début du XVII ${ }^{\mathrm{e}}$ siècle, et qui se sont tenus des deux côtés de l'Atlantique, sur la chrétienté éthiopienne est surprenant compte tenu du nombre important d'études qui analysent les vifs débats entre missionnaires jésuites en Éthiopie au XVI et au $\mathrm{XVII}^{\mathrm{e}}$ siècles ainsi que la vision fantasmée de l'histoire éthiopienne promue par des penseurs ibériques qui n'avaient jamais mis les pieds en Afrique. On pense en particulier au jésuite établi en Éthiopie Pedro Páez (1564-1622) et au dominicain de Valence Luis de Urreta (1570-1636) ${ }^{13}$. Si des travaux de recherche de grande ampleur ont éclairé l'histoire et l'archéologie des missions jésuites en Éthiopie au $\mathrm{XVI}^{\mathrm{e}}$ siècle ainsi que les relations entre les jésuites établis en Éthiopie et les dirigeants éthiopiens, ces études ne s'intéressent guère à la manière dont différentes visions de l'Éthiopie ont été construites ou diffusées par les penseurs ibériques qui sont restés bien loin de l'Éthiopie elle-même ${ }^{14}$. Et pourtant, le livre d'Alonso de Sandoval Naturaleza, policia sagrada i profana, costumbres i ritos, disciplina $i$ catechismo evangelico de todos Etiopes (1627) faisait partie d'une intense campagne transatlantique que Sandoval a menée pour assurer le baptême correct des Africains noirs, asservis et libres. Sandoval a publié sa correspondance écrite avec les autorités religieuses et royales du monde ibérique - y compris les prêtres en Afrique - pour sensibiliser aux problèmes théologiques qui se posaient lorsque des hommes et des femmes noirs esclaves et libres vivaient en chrétiens, mais n'avaient pas été correctement baptisés ${ }^{15}$. Ce faisant, Sandoval a déclenché une discussion transatlantique sur la signification et l'importance du christianisme éthiopien dans le monde ibérique atlantique du début du XVII ${ }^{\mathrm{e}}$ siècle.

Ce silence peut en partie se comprendre en lien avec la domination de certaines conceptions historiographiques sur les notions de race et d'exclusion ou, comme l'explique Matteo Salvadore dans une étude importante sur les relations entre l'Europe et l'Éthiopie aux XV ${ }^{\mathrm{e}}$ et $\mathrm{XVI}^{\mathrm{e}}$ siècles, les «modèles

13. Isabel BoAvidA, Hervé PEnnec, Manuel João Ramos, "Introduction», in Pedro Páez's History of Ethiopia, 1622, Burlington, Ashgate, 2011, p. 1-58; Antoine BoUBA KIDAKOU, "Juan de Baltasar Abissinio y la literatura hispanoafricana en el siglo XVII", Diversité et identité culturelle en Europe, 8-1, 2011, p. 137-150. Luis DE URRETA, Historia eclesiastica, politica, natural y moral, de los grandes y remotos reynos de la Etiopia, Monarchia del Emperador, llamado Preste Iuan de las Indias muy util y prouechosa para todos estados, principalmente para predicadores [...] compuesta por [...] Luys de Vrreta, de la sagrada Orden de Predicadores; con tres tablas muy copiosas, En Valencia: en casa de Pedro Patricio Mey: a costa de Philippo Pincinali [...], 1610, Complutense Library University of Madrid.

14. Víctor M. FERnÁndez, Jorge DE TORRES, Andreu MARTínez D’ALÒs-Moner, Carlos CAÑETE JimÉnEZ, The Archaeology of The Fesuit Missions In Ethiopia (1557-1632), Leyde, Brill, 2017. "Introduction", Pedro Páez's History Of Ethiopia, art. cit.; L. CoHEN, The Missionary Strategies Of The fesuits In Ethiopia, Wiesbaden, Harrasowitz Verlag, "Aethiopistische Forschungen", 2009. Hervé PENNEC, "Missionary knowledge in context: geographical knowledge of Ethiopia in dialogue during the $16^{\text {th }}$ and $17^{\text {th }}$ Centuries ", in Adrien Delmas, Nigel Penn (éd.), Written Culture In A Colonial Context; Africa And The Americas 1500-1900, Leyde, Brill, 2012, p. 73-96. Voir aussi Verena KREBs, Medieval Ethiopian Kingship, Craft, and Diplomacy with Latin Europe, New York, Palgrave Macmillan, 2021 ; Matteo SALvadore, The African Prester Fohn and the Birth of Ethiopian-European Relations, 1402-1555, Londres, Routledge, 2017.

15. SANDOVAL, Naturaleza, policia sagrada i profana. Voir par exemple, Livre III, chap. XXII, fols, 326v-334v. Berta AREs QUEIJA, «La Cuestión Del Bautismo De Los Negros En El Siglo XVII: La Proyección De Un Debate Americano» (http://digital.csic.es/bitstream/10261/57537/1/Binder1.pdf). 
d'analyse hégémoniques, en particulier ceux qui souscrivent à l'idée plus large que les préjugés fondés sur la couleur de peau sont des constantes générales et éternelles dans les relations entre l'Europe et l'Afrique", laquelle "ne correspond guère à la réalité des échanges» entre Africains et Européens au XV et au XVI ${ }^{\mathrm{e}}$ siècle $^{16}$. En effet, les travaux qui explorent les points de vue sur la race au prisme des discours intellectuels du monde ibérique de cette période (les débats théologiques en particulier) ont tendance à postuler que les auteurs de la période adhéraient à une vision unanime de pureté du sang, laquelle considérait que les Noirs étaient porteurs d'un sang irrémédiablement souillé. Une telle tache était supposée interdire aux Noirs toute revendication du statut de Vieux chrétien et les condamnait à l'exclusion sociale dans le monde ibérique ${ }^{17}$.

Cette lecture masque cependant le fait qu'il existe un éventail plus large de discours théoriques, souvent contradictoires, autour des origines des Africains noirs, qui circulent dans le monde ibérique du XVI ${ }^{\mathrm{e}}$ et du début du XVII ${ }^{\mathrm{e}}$ siècle. Comme Salvadore et d'autres chercheurs l'ont démontré, l'Italie et le monde ibérique $\mathrm{du} \mathrm{XV}^{\mathrm{e}}$ siècle ne manquaient pas de curiosité à propos de l'Éthiopie et témoignent de l'existence d'une théorie alternative des origines des Africains noirs tout à fait intéressante, à savoir l'existence d'une ancienne Église chrétienne noire ${ }^{18}$. Certains écrivains, comme Alonso de Sandoval, ont défendu l'idée d'une ancienne Éthiopie chrétienne afin de catégoriser les Africains noirs non seulement comme de Vieux chrétiens, mais aussi comme les premiers chrétiens.

16. M. Salvadore, The African Prester fohn..., op. cit., p. 10.

17. Nikolaus BötTCHer, Bernd HAusBerger, Max S. HERING TorRes, «Introducción: Sangre, mestizaje y nobleza", in EID. (éd.), El peso de la sangre. Limpios, mestizos y nobles en el mundo hispánico, Mexico City, El Colegio de México, 2012, p. 9-28; M. S. Hering TorREs, "Purity of Blood: Problems of Interpretation", in M. S. HERING TORRES, María Elena MARTínEZ, David NiRENBERG (éd.), Race and Blood in the Iberian World, Zurich, LIT Verlag, 2012, p. 11-38; Antonio FERos, Speaking of Spain, The Evolution of Race and Nation in the Hispanic World, Cambridge, Harvard University Press, 2017, p. 143; Alejandro E. GÓMEZ, "El estigma africano en los mundos hispano-atlánticos (siglos XIV al XIX)", Revista de Historia, 153, 2005, p. 139-179; Tamar HerZoG, Defining Nations: Immigrants and Citizens in Early Modern Spain and Spanish America, New Haven, Yale University Press, 2003. M. E. MARTíneZ, Genealogical Fictions. Limpieza de Sangre, Religion, and Gender in Colonial Mexico. Stanford, Stanford University Press, 2008.

18. L. Brewer-García, "Hierarchy And Holiness", op. cit.; Miriam Eliav-Feldon, Renaissance Impostors And Proofs Of Identity, New York, Palgrave Macmillan, 2012, p. 68-96; Carmen FRACCHIA, "Black But Human". Slavery And Visual Arts In Habsburg Spain, 1480-1700, Oxford, Oxford University Press, 2019; Kate Lowe, «Representing Africa: Ambassadors And Princes From Christian Africa To Renaissance Italy And Portugal, 1402-1608", Transactions Of The Royal Historical Society, 17, 2007, p. 101-128; Jonathan K. NELSON, «Ethiopian Christians on the Margins: Symbolic Blackness in Filippino Lippi's Adoration of the Magi and Miracle of St Philip", Renaissance Studies, Early View, 16, 2021 (https:// doi.org/10.1111/rest.12722); Manuel Jõ̃o RAMOs, «O Destino Etíope Do Preste João: A Etiópia Nas Representações Cosmográficas Europeias ", in Fernando CRISTOVÃo (éd.), Condicionantes Culturais Da Literatura De Viagens: Estudos E Bibliografias, Lisboa, Edições Cosmos, 1999, p. 235-259; Manuel JoÃo Ramos (éd.), Carta Do Preste foão Das Indias, Pavilhão De Portugal, Assirio \& Alvim, 1998; Manuel JoÃo Ramos, Essays In Christian Mythology. The Metamorphosis Of Preste Fohn, Lanham, University Press Of America, 2006; Matteo SAlvadore, The African Prester Fohn..., op. cit.; Elaine SANCEAU, The Land Of Prester Fohn. A Chronicle Of Portuguese Exploration, New York, Alfred A. Knopff, 1944; E. Rowe, Black Saints In Early Modern Global Catholicism, op. cit. 


\section{LA JUSTIFICATION THÉOLOGIQUE DE L'ESCLAVAGE}

\section{L'histoire chrétienne de l'Éthiopie selon Sandoval}

Pour comprendre la manière dont Alonso de Sandoval s'est servi de l'histoire mythique de l'Éthiopie chrétienne afin de justifier l'asservissement brutal de tous les Africains noirs ainsi que leur arrachement forcé à l'Afrique, il est nécessaire de revenir sur le rôle de l'Éthiopie au sein de son raisonnement théologique. L'auteur fait en premier lieu des Éthiopiens un terme qui désigne tous les Africains à peau noire, arguant que l'étymologie du nom Éthiopie signifie tout simplement "visage ou peau brûlé(e) [rostro quemado] ${ }^{19}$. Il affirme en outre qu'il est "pratique de désigner tous les peuples de couleur noire comme éthiopiens", tout en faisant remarquer que chacun d'entre eux, parmi lesquels les peuples "guinéen, kalabari, lucumi, congolais, angolais, cafres, makua, et d'autres", conservent leurs caractéristiques propres ${ }^{20}$. En second lieu, Sandoval insiste sur le fait que l'Éthiopie est la toute première Église chrétienne, celle qui fut élue par Dieu lui-même ${ }^{21}$. Sandoval explique ainsi que le verset du chapitre 87 des Psaumes, "Athiopia preveniet manuseius Deo", relate la manière dont Dieu a fondé sa première Église en Éthiopie ${ }^{22}$. Il affirme que, parmi toutes les nations diverses et savantes, Dieu "a tendu la main aux Noirs pour qu'ils fondent son Église et reçoivent l'Évangile afin de servir d'attrait et d'exemple pour les autres nations $»^{23}$. Sandoval conclut sa description des différentes régions, langues et cultures d'Afrique dans le Livre I en les présentant comme des territoires sous le contrôle du prêtre Jean et de l'Éthiopie chrétienne, et affirme dans le Livre II que «dans les ténèbres, l'obscurité et la noirceur de ces Éthiopiens réside la majesté de Dieu... car Dieu vit avec grand bonheur au milieu de ces nations... Dieu ne déteste pas ces terres parce qu'elles sont noires et peuplées de ténèbres " ${ }^{24}$.

Sandoval s'inscrit ici au sein de la tendance, chez des artistes, cartographes et théologiens de la fin du XV ${ }^{\mathrm{e}}$ siècle et du XVI ${ }^{\mathrm{e}}$ siècle, à confondre les récits bibliques de l'Éthiopie avec ceux qui se rapportent à un monarque chrétien mythique, le prêtre Jean, renforçant ainsi le poids, dans l'Europe catholique de l'époque, des théories chrétiennes sur les origines éthiopiennes des Africains noirs au $\mathrm{XVI}^{\mathrm{e}}$ siècle $^{25}$. Artistes, cartographes et théologiens de l'Europe catholique au $\mathrm{XVI}^{\mathrm{e}}$ siècle se mirent ainsi à mettre en scène des mélanges de récits bibliques sur

19. A. SANDOval, Naturaleza, policia sagrada i profana, op. cit., Livre I, Chap. II, fol. 10.

20. Ibidem.

21. Ibidem, Livre II, Chap. VI, fol. 147r.

22. Ibidem.

23. Ibidem, Livre II, Chap. VI, fols. 147-150.

24. Ibidem, Livre I, Chap. XXIII, fol. 89v; Ibidem, Livre II, Chap. XXIII, fol. 227.

25. M. Salvadore, The African Prester Fohn..., op. cit., p. 10. M. JoÃo Ramos (éd.), Carta Do Preste foão, op. cit.; ID., Essays In Christian Mythology..., op. cit.; M. ElIAV-FELdON, Renaissance Impostors..., op. cit.; M. JoÃo Ramos, "O destino etíope do Preste João", art. cit.; E. SANCEAU, The Land Of Prester fohn, op. cit.; K. LOWE, "Representing Africa», art. cit. Pour un exemple qui illustre la fusion imaginaire entre le prêtre Jean et le christianisme éthiopien au milieu du XVI ${ }^{\mathrm{e}}$ siècle, voir Francisco ÁlvARES, $H o$ Preste Ioam Das Indias, Em Casa De Luis Rodriguez, 1540, Bibliothèque nationale du Portugal, ID 22430. 
l'Afrique à travers trois monarques: le prêtre Jean, le mage Balthazar (que l'Évangile de saint Matthieu décrit comme l'un des trois rois mages qui rendent visite à Jésus juste après sa naissance, les bras chargés d'or, d'encens et de myrrhe) et Elesbaan (un monarque chrétien du $\mathrm{VI}^{\mathrm{e}}$ siècle qui régna sur le royaume d'Aksoum dans le nord de l'Éthiopie) ${ }^{26}$. Ainsi, à partir du XV $\mathrm{XV}^{\mathrm{e}}$ siècle, le mage Balthazar, jusqu'alors représenté comme un monarque d'Asie de l'Est, acquiert les traits que les stéréotypes typiquement euro-chrétiens de la physionomie attribuent aux Africains noirs ${ }^{27}$. Quant aux artistes et cartographes de la fin du XVI ${ }^{\mathrm{e}}$ siècle, ils représentent de manière de plus en plus systématique l'Éthiopie comme un royaume chrétien ancien sous le gouvernement d'un prêtre Jean noir, représenté lui aussi selon une vision en tout point conforme aux clichés européens sur la physionomie africaine ${ }^{28}$.

D'autres penseurs religieux diffusent aussi l'idée d'un roi chrétien noir puissant et éternel qui règne sur l'Éthiopie et assimilent ainsi les trois monarques noirs que sont Elesbaan, le prêtre Jean et Balthazar avec l'histoire de la chrétienté éthiopienne. Ainsi, dans son Historia eclesiastica politica, natural y moral de los... Reynos de la Etiopia, monarchia del... preste Fuan de las Indias imprimée à Valence entre 1609 et 1610, le frère dominicain Luis de Urreta présente une histoire de l'Éthiopie gouvernée par de puissants monarques noirs dont les noms composés renvoient souvent à ceux du prêtre Jean, du mage Balthazar et du roi Elesbaan ${ }^{29}$. Il explique que son savoir sur l'histoire éthiopienne lui vient de la venue «dans ce saint couvent de prêcheurs de la noble ville de Valence, d'un gentleman éthiopien du royaume et de la ville de Fatigar en Éthiopie appelé Iuan de Baltasar, un chevalier militaire de l'Ordre de Saint-Antoine l'Abbé et de la garde du roi d'Éthiopie appelé Prêtre Jean des Indes». Urreta fait ainsi reposer la crédibilité de son texte sur un messager dont le nom,

26. Pour une discussion approfondie de l'inclusion des anciens saints éthiopiens tels qu'Elesbao et Ephigénie dans l'ouvrage de Cesare Baronio (m. 1607), Martyrologium Romanum ad novam kalendarii rationem, 1586, voir Erin K. Rowe, Black Saints in Early Modern Global Catholicism, Cambridge, Cambridge University Press, 2019, p. 26-32.

27. Vicenzo FOPPA, "L'Adoration des rois mages", (autour de 1500), National Gallery, Londres, Room 55, NG729 (www.nationalgallery.org.uk/paintings/vincenzo-foppa-the-adoration-of-the-kings); Atelier de Jan GOSSAERT, "L'Adoration des rois mages" (début du XVI ${ }^{\mathrm{e}}$ siècle), prêté par une collection privée à la National Gallery, Londres, Room 14, L878. Paul KAPLAN, The Rise of the Black Magus in Western Art, Ann Arbor, University of Michigan Press, 1985; Joseph Leo KoERNER, "The Epiphany of the Black Magus Circa 1500", in David BIndman, Henry Louis GATES JR. (éd.), The Image of the Black in Western Art, Volume III, From the "Age of Discovery" to the Age of Abolition, Part I: Artists of the Renaissance and the Baroque, Cambridge, Harvard University Press, 2010, p. 7-92; J. K. NeLsON, "Ethiopian Christians on the margins", art. cit.

28. Ioannis ORLA, "Gravure Il Preteianni, Re d'Ethiopia (Le prêtre Jean, roi d'Éthiopie)" (1599), Image of the Black in Western Art, Hutchins Center, Harvard, USA, ID 10099; Abraham ORTELIUS, 1527-1598, "Presbiteri Iohannis, sive, Abissinorum Imperii descriptio", tiré de Theatrum orbis terrarium... d'ORTEliUs (Anvers, 1603), Princeton University Library, Historic Maps Collection, référence: Norwich, Africa 11; Gerard MERCATOR (1565-1656), "Abissinorum sive Pretiosi foannis imperiu", (Amsterdam, Jodocus Hondius, 1613), Stanford University Library, Renaissance Map Collection. Jean Michel Massing, "Mapping Africa", in David Bindman, Henry Louis Gates JR, Karen C. Dalton (éd.), The Image of the Black in Western Art, Volume III: From the "Age of Discovery" to the Age of Abolition, Part 2: Europe and the World Beyond, Cambridge, Harvard University Press, 2011, chap. 4.

29. L. DE URRETA, Historia eclesiastica, politica, natural y moral..., op. cit. 
Iuan Balthasar, entremêle la légende du prêtre Jean et celle du roi mage ${ }^{30}$. En outre, dans sa description de l'histoire de l'Éthiopie, il soutient que la gloire de l'Église chrétienne d'Éthiopie commence par la naissance du Christ et les trois Rois Mages, qui ont chacun cherché refuge en Éthiopie et dont les descendants ont ensuite régné sur les différents royaumes éthiopiens sous la figure de prêtres Jean éternels; un conte qui confond la légende du prêtre Jean avec celle des Rois Mages pour créer un roi chrétien noir intemporel qui aurait régné tout au long de l'histoire du christianisme éthiopien depuis la naissance du Christ ${ }^{31}$. De plus, Urreta assimile l'ancien saint éthiopien d'Elesbaan avec la légende du prêtre Jean, en relatant comment le prêtre Jean Elesbaan aurait massacré un roi juif traître: «Cette cruauté et cette trahison du Juif impie ainsi que la nouvelle des dégâts dans la ville arrivèrent aux oreilles du prêtre Jean Elesbaan, qui était le souverain et le maître non seulement de l'Éthiopie mais aussi de la plus grande partie de l'Arabie "32. Urreta s'appuie ici sur la relativement brève inclusion d'Elesbaan dans le Martyrologium Romanum ad novam kalendarii rationem (1586) publié peu de temps auparavant par Cesare Baronio (m. 1607), mais il y ajoute sa propre interprétation fantaisiste en décrivant Elesbaan comme le prêtre Jean Elesbaan. Les amalgames d'Urreta entre les figures du prêtre Jean et du mage Balthazar d'une part, entre le prêtre Jean et le roi Elesbaan d'autre part, sont révélateurs de sa tentative de dépeindre un monarque noir puissant et éternel régnant sur l'Éthiopie chrétienne.

L'argument de Sandoval selon lequel Dieu a choisi l'Éthiopie comme lieu de la première Église chrétienne s'inscrit donc dans la tradition des théologiens contemporains qui imaginent l'histoire chrétienne éthiopienne bien qu'ils n'aient jamais voyagé dans la région. Mais Sandoval estime que l'Éthiopie s'est convertie au christianisme bien plus tôt encore, et qu'elle fut la première nation du monde à tendre la main vers Dieu, qui lui fit l'honneur d'y établir sa première Église et d'en faire ainsi la nation destinée à guider toutes les autres sur le chemin de l'Évangile. C'est ainsi que Sandoval développe une séduisante théorie de l'origine des Africains à peau noire, théorie qui deviendra la pierre angulaire de sa justification de l'esclavage. S'appuyant sur la naissance de Moïse telle qu'elle est décrite dans le chapitre 2 de l'Exode, Sandoval explique que Moïse se réfère à la fondation de l'Église éthiopienne telle qu'elle est prophétisée

30. Ibidem, "Prologo». Voir aussi Mar REy BuEno, "Juan de Baltasar, caballero abisinio. Utopías etíopes en la Valencia del seiscientos ", Pasiones bibliográficas II, València, Societat Bibliogràfica Valenciana Jerònima Galés, p. 115-123; Isabel BoAvidA, Hervé PENNEC, Manuel João RAMOs, "Introduction", in Pedro Páez's History of Ethiopia, 1622, Burlington, Ashgate, 2011, p. 1-58; Antoine Bouba KIDAKOU, "Juan de Baltasar Abissinio y la literatura hispanoafricana en el siglo XVII", Diversité et identité culturelle en Europe, 8-1, 2011, p. 137-150.

31. L. DE URRETA, Historia eclesiastica, politica, natural y moral..., op. cit.

32. Ibidem, p. 680. Cité par Enrique Martínez LóPEZ, Tablero de Ajedrez: imágenes del negro heroico en la comedia españnola y en la literatura e iconografía sacra del Brasil esclavista, Lisbonne, Fundação Calouste Gulbenkian, 1998, p. 68. Cité et traduit en anglais dans John BEUSTERIEN, An Eye on Race. Perspectives from Theater in Imperial Spain, Lewisburg, Bucknell University Press, 2016, p. 132. 
aux psaumes 71 et 86 , et par le Cantique des cantiques $1: 5$. Moïse y prend note de la beauté de la couleur noire ${ }^{33}$ :

«Ecce alienigena et Tyrus, et populus, Aethiupum, sifuerunt illic-parmi des premières pierres qui servirent de fondations de ce divin ouvrage, on compte la nation éthiopienne - une pierre qui, bien que noire, était magnifiquement brillante et précieuse ${ }^{34}$.

Selon Sandoval, les Éthiopiens eux-mêmes auraient suggéré ce lien entre le noir et la beauté:

«Nigra sunt [sic], sed formosa filice [sic] Ierusalem, ideo dilexit me rex - bien que noirs, nous sommes un peuple, et même, un peuple que Dieu estima tant qu'il voulut que l'Éthiopie fût parmi les premières, voire la première à lui donner sa main en fiançailles, et ses premières pierres pour fonder sa ville, et la première appelée par lui, et la première à l'adorer ${ }^{35}$.

Après avoir établi que l'Éthiopie est la première nation à avoir adopté l'Évangile pendant cet "âge d'or», Sandoval demande s'il est plus bel éloge que l'on puisse faire à une nation. Oui, répond-il ${ }^{36}$. Il évoque la manière dont la nation éthiopienne a guidé les autres sur le chemin du christianisme: "[La nation éthiopienne] fut (pour ainsi dire) le "manso" (comme on l'appelle) du troupeau de Dieu ${ }^{37}$, celui qui guida les autres et leur enseigna, en suivant le chemin droit et juste, la loi de l'Évangile. [L'Éthiopie] était comme le maître des autres nations ${ }^{38}$. En décrivant tous les individus à la peau foncée comme des Éthiopiens, Sandoval, en plus de reprendre l'argument selon lequel l'Éthiopie fut la première Église chrétienne, rejette toute possibilité que les Noirs d'Afrique ne soient pas des Vieux chrétiens ou que leur sang soit souillé. Au contraire: les Africains descendent de la première Église chrétienne élue par Dieu et bénéficient d'un régime de faveur de la part de Dieu, au nom de la Vierge.

À partir d'amalgames et de confusions courantes à son époque entre l'histoire de l'Éthiopie et l'image d'un roi noir éternel et puissant, Sandoval sous-entend que le mage Balthazar était éthiopien quand il écrit: "comme dans la prophétie de David, parmi les trois rois qui adorèrent [Jesus Christ], l'un était noir»39. Or le pouvoir d'un Balthazar éthiopien tiendrait aux relations entre la Vierge Marie et la nation éthiopienne. Sandoval suggère en effet que la loyauté sans faille de Marie envers l'Éthiopie vient du fait que Balthazar l'a reconnue comme étant la mère de Dieu et a couvert son fils Jésus de cadeaux et d'amour malgré le

33. D'autres chercheurs se sont interrogés sur la vision de la beauté noire que développe Sandoval dans d'autres contextes. Voir notamment Grace HARPSTER, "The Color of Salvation: The Materiality of Blackness in Alonso de Sandoval's De instauranda Aethiopum Salute», in Pamela A. PATTON (éd.), Envisioning Others. Race, Color, and the Visual in Iberia and Latin America, Leyde, Brill, 2016, p. 83-110; L. BREWER-GARCÍA, «Imagined Transformations: Color, Beauty, and Black Christian Conversion in Seventeenth-Century Spanish America", in Envisioning Others..., op. cit., p. 111-141.

34. A. SANDOval, Naturaleza, policia sagrada i profana, Livre II, Chap. VI, fol. 147v.

35. Ibidem.

36. Ibidem.

37. En espagnol, le «manso» est le nom technique pour désigner l'animal le plus docile, celui qui sert de guide dans un troupeau [note du traducteur].

38. Ibidem, fol. $147 \mathrm{v}$.

39. Ibidem, Livre II, Chap. VI, fols. $147 \mathrm{v}-148 \mathrm{r}$. 
dénuement des circonstances de la naissance de l'enfant ${ }^{40}$. Comme le fait remarquer Sandoval, "ayant été incluse dans l'Adoration que le roi noir montrait comme les deux autres pour son fils unique nouveau-né, elle se sentit sans aucun doute son obligée pour l'honneur qu[e Balthazar] fit à son fils, l'obéissance dont il fit preuve et les cadeaux qu'il présenta ${ }^{41}$. Sandoval suggère que la Vierge est redevable au monarque noir et à sa nation parce que Balthazar a reconnu son enfant comme le fils de Dieu: «il faut toujours présumer que cette Princesse Reine... estime et apprécie le trône de Sa Majesté et la noblesse [du roi noir] qui l'a reconnue comme mère de Dieu au milieu du foin, près des animaux et d'une mangeoire» ${ }^{42}$.

Sandoval affirme que la dette de Marie envers Balthazar crée un lien d'amour indissoluble entre la Vierge et la nation éthiopienne ${ }^{43}$. Il raconte que la première Église d'Éthiopie a été construite pour vénérer Marie, en échange de quoi la Vierge a promis de nombreuses faveurs à Balthazar et sa nation: «Sans aucun doute il fut entendu que la Vierge parlerait [au roi noir] avec une grande familiarité, lui octroierait de grandes largesses en leur promettant, à lui et sa nation, de nombreuses faveurs $»^{44}$. La gratitude transforme ainsi la Vierge en instance protectrice de la nation éthiopienne, et les Éthiopiens reconnaissants en adorateurs fidèles de $\mathrm{Marie}^{45}$. Pourrait-on imaginer meilleures preuves, demande Sandoval à titre purement rhétorique, des bontés incommensurables dont Marie et Jésus ont fait profiter l'Éthiopie?

«Et en retour de ces faveurs immenses, nous savons grâce à des récits authentiques que la première Église que les Abyssiniens ont construite dans leur Éthiopie était celle de la très sainte Vierge et ce pendant que cette royale Souveraine était vivante, et sa vocation fut S. María du Mont Sion ${ }^{46}$.

Sandoval ne se contente donc pas de présenter le mage Balthazar comme un Éthiopien: il suggère également que les vies de Jésus et Marie sont inextricablement liées au monarque noir de la nation éthiopienne. Cette attention particulière accordée à la relation entre Marie et Balthazar se retrouve dans le frontispice de l'édition de 1647 de son traité, une illustration par Juan de Noort du mage noir dans une scène de l'Adoration des mages ${ }^{47}$. L'image s'accompagne de la prophétie tirée de Psaumes 67 ("Ethiopia praeveniet manus eius deo") que Sandoval analyse dans le chapitre 6 du livre 2 et résume comme suit: "Praeveniet" signifie que Dieu a donné sa main et son amitié aux Éthiopiens et qu'ils font partie des premières nations du monde ${ }^{48}$. La même prophétie était également imprimée

40. Ibidem, Livre II, Chap. VIII, fols. 153-153v.

41. Ibidem.

42. Ibidem.

43. Ibidem, Livre II, Chap. VIII, fol. 153v.

44. Ibidem.

45. Ibidem.

46. Ibidem

47. A. SANDoval, Tomo primero De instauranda aethiopum salute..., op. cit. Pour une autre analyse de ce même frontispice, voir L. BREWER-GARCÍA, "Imagined Transformations...", art. cit. 48. A. Sandoval, Naturaleza, policia sagrada i profana..., op. cit., Livre II, Chap. VI, fols. 147-150. 
sur le frontispice de $1627^{49}$. La citation qui orne les frontispices des deux éditions (celle de 1627, et celle qui accompagne l'image de Balthazar dans le traité de 1647) résume la thèse de Sandoval: l'Éthiopie est la première nation à avoir accepté l'Évangile et la main de Dieu, guidant ensuite les autres nations sur le chemin du christianisme.

\section{Controverses théologiques: la justification de l'esclavage par Sandoval}

Chez Sandoval, la justification de l'esclavage est liée à son argument au sujet de l'Église primitive d'Éthiopie. Si les Africains noirs avaient été des non-chrétiens, comme les Amérindiens, leur asservissement eût été illégitime. C'est d'ailleurs l'argument que Bartolomé de Las Casas avançait dans sa campagne contre l'esclavage des Africains noirs ${ }^{50}$. Las Casas était devenu célèbre au milieu du $\mathrm{XVI}^{\mathrm{e}}$ siècle pour son opposition à l'esclavage des Amérindiens, qui aboutit à la promulgation des Nouvelles lois de 1542-45, lesquelles interdisaient l'asservissement des indigènes du continent américain, nécessairement injuste puisqu'ils n'avaient jamais été exposés au christianisme ${ }^{51}$. Il estimait l'asservissement des Africains tout aussi injuste pour les mêmes raisons ${ }^{52}$. En 1552, il critiqua sans ménagement la traite des Africains dans sa Brevisima Relacion de la Destruccion de Africa ${ }^{53}$. Selon lui, aucune base légale ou théologique n'existait pour justifier l'asservissement des «Noirs et des Maures» par les commerçants portugais sur la côte et les terres intérieures d'Afrique de l'Ouest, car ces régions étaient des terres païennes sans aucun contact préalable avec le christianisme, ce qui rendait l'asservissement des Africains noirs essentiellement injuste - argument antiesclavagiste radical parallèle à celui développé pour les indigènes américains ${ }^{54}$.

49. Ibidem.

50. B. Las Casas, Brevisima Relacion De La Destruccion De Africa; Preludio De La Destrucción De La Indias. Primera Defensa De Los Guanches Y Negros Contra Su Esclavización, Salamanque, Lima, Isacio PÉREZ FERNANDEZ (éd.), 1989, p. 253-256.

51. Nancy VAn DeUSEN, Global Indios. The Indigenous Struggle for Fustice in Sixteenth-Century Spain, Durham, Duke University Press, 2015. Karen GRAUBART, «As Slaves and Not Vassals: Interethnic Claims of Freedom and Unfreedom in Colonial Peru. Como esclavos y no vasallos: reclamaciones interétnicas y nolibertad en el Perú colonial", Población $\mathcal{E}$ Sociedad, 27-2, 2020, p. 30-53 (http://dx.doi. org/10.19137/pys-2020-270203).

52. B. LAs CAsas, Brevisima Relacion De La Destruccion De Africa..., op. cit. Rubén SÁnCHEZGodoy, El Peor De Los Remedios: Bartolomé De Las Casas Y La Critica Temprana A La Esclavitud Africana En El Atlántico Ibérico, Pittsburgh, Instituto Internacional De Literatura Iberoamericana / University Of Pittsburgh, 2016; Clara CAMPLANI, "La Defensa De Los Negros en Bartolomé De Las Casas", in Victorien Lavou Zoungbo (éd.), Bartolomé De Las Casas face à l'esclavage des Noir-e-s en Amériques/ Caraïbes, L'aberration du onzième remède (1516), Perpignan, Presses universitaires de Perpignan, 2011, p. 89-98; R. SÁnCHEZ-Godoy, «Bartolomé De Las Casas Crítico De Las Esclavizaciones Portugueses En Las Islas Canarias Y La Costa Occidental De África", in ibidem, p. 135-155; Juliana Beatriz ALMEIDA DE SouzA, "Las Casas, Alonso de Sandoval", art. cit., p. 31-37.

53. B. Las CASAs, Brevisima Relacion de la Destruccion de Africa..., op. cit., p. 253-256. Pour un résumé, voir également J. B. Almeida DE SOUZA, "Las Casas, Alonso de Sandoval», art. cit. p. 31-37.

54. Chloe L. IRETON, «Black Africans’ Freedom Litigation Suits to Define Just War and Just Slavery in the Early Spanish Empire", Renaissance Quarterly, 73-4, 2020, p. 1278-1320. Pour les positions d'un autre théologien du XVI ${ }^{\mathrm{e}}$ siècle qui se prononça sur le caractère illégitime de l'esclavage des Africains noirs, voir la lettre adressée au roi par Fray Alonso de Montúfar's (1489-1572), dans Manuel LUCENA 
Par contraste, la justification par Sandoval de ce même asservissement vient de sa conviction que les Africains ont été exposés au christianisme en leur qualité de descendants des chrétiens d'Éthiopie, alors même que l'Église d'Éthiopie subissait un déclin sévère partout en Afrique (c'est en tout cas ce à quoi il consacre des parties importantes des livres 1 et 2 de son traité ${ }^{55}$ ). Sandoval affirme que l'étendue de ce déclin et de cette corruption est telle que de nombreux Africains ne sont même plus au courant de leurs origines chrétiennes. Dans le livre 1 de son traité, il détaille des exemples de cette corruption en mettant l'accent sur l'incivilité, la barbarie et l'impiété de différentes sociétés africaines dans toutes les parties connues du continent ${ }^{56}$. Il considère que l'ampleur de ce déclin signifie que les Catholiques ibériques, et en particulier les jésuites, ont un rôle central à jouer pour rendre son salut à l'âme des Éthiopiens, ce qui sera l'objet des livres 3 et 4 . On retrouve évidemment cette préoccupation dans le titre de la version révisée du traité de 1647, De Instauranda Athiopum Salute ${ }^{57}$. Ainsi, dans le livre 4, Sandoval décrit le rôle important dévolu à la Compagnie de Jésus tout au long de son histoire dans la restauration de l'âme des Éthiopiens. Il revient en particulier sur les missions menées par les jésuites en Éthiopie à la fin du $\mathrm{XVI}^{\mathrm{e}}$ siècle et toujours en cours au moment où il écrit, qu'il érige en exemple de la mission globale des jésuites pour sauver l'âme des Éthiopiens ${ }^{58}$.

\section{UNE OPÉRATION DE CONVERSION}

\section{La possibilité donnée aux Africains noirs de recouvrer leur christianisme originel}

Sandoval est convaincu que les Africains noirs ont la possibilité de retrouver leur ancienne gloire de chrétiens d'Éthiopie par le truchement de l'esclavage, du baptême et d'une direction religieuse appropriée. Il s'appuie en ceci sur la biographie de deux figures noires célébrées dans l'Europe du XVI ${ }^{\mathrm{e}}$ siècle comme des exemples parfaits d'Éthiopiens "restaurés", qui rendent grâce à Dieu pour sa capacité à transformer en "grands saints» des «noirs païens, barbares, indomptés, incultes et sauvages", et à faire d'"Éthiopiens, des religieux de l'Ordre séraphique ${ }^{59}$. En présentant des hommes noirs connus et vénérés comme des Éthiopiens à la gloire restaurée, Sandoval entend prouver sa

\footnotetext{
SAlmoral (éd.), Regulación de la esclavitud negra en las colonias de América Española (1503-1886): Documentos para su estudio, Alcalá, Université d'Alcalá de Henares, 2005, p. 88-89; Pablo Miguel SIERRA SILVA, Urban Slavery in Colonial Mexico Puebla De Los Ángeles, 1531-1706, Cambridge, Cambridge University Press, 2018, p. 40-42. Voir aussi Luiz Felipe DE AlenCASTRO, «Portuguese Missionaries and Early Modern Antislavery and Proslavery Thought", in Josep M. FRADERA, Christopher SCHMIDT-NowARA (éd.), Slavery And Antislavery In Spain's Atlantic Empire, New York, Berghahn Books, 2013, p. 43-73.

55. A. SANDoval, Naturaleza, policia sagrada i profana..., op. cit., Livres I et II.

56. Ibidem, Livre I.

57. Ibidem, Livre II, fols. 228-334v, et Livre IV, fols. 1-81 [nouvelle foliation]. A. SANDovaL, Tomo primero De instauranda aethiopum salute, op. cit.

58. A. SANDOval, Naturaleza, policia sagrada i profana..., op. cit., Livre IV, fols. 1-81.

59. Ibidem, Livre I, Chap. XXXII, fols. 128v-130v: Vida de dos bienaventurados confessores Antonio, y Benedito, Etiopies, Religiosos de la Serafica Orden.
} 
théorie ${ }^{60}$. À cet effet, il utilise en premier lieu Benito de Palermo, en français Benoît le More (1526-1589), Noir libre né en Sicile dont la piété a engendré la gloire posthume et qui a fait l'objet d'une ardente vénération parmi les communautés noires partout dans le monde ibérique au XVI ${ }^{\mathrm{e}}$ siècle et au-delà61.

S'inspirant largement d'une hagiographie de San Benito publiée par le frère Antonio Daza, établi à Valence, dans une anthologie de vies remarquables de membres de l'ordre franciscain intitulée Quarta Parte de la Chronica General $(1612)^{62}$, Sandoval décrit Benoît comme un esclave noir né en Sicile dont la dévotion et la vie (contemplative et active) a surpassé celle de tous ses contemporains au point que les pères de la province le nommèrent Gardien du Couvent de Jésus dans la ville de Palerme ${ }^{63}$. De plus, poursuit Sandoval, Benoît était si «illustre», et béni par Dieu d'une telle grâce que les érudits recherchaient ses conseils quand ils faisaient face à des questions ou des difficultés dans l'interprétation de l'Écriture. Enfin, Dieu accorda à Benoît la capacité de faire des miracles et des prophéties. Sandoval rappelle que Benoît a ressuscité un enfant, rendu la vue à un aveugle et guéri plusieurs individus atteints de diverses pathologies ${ }^{64}$. Sandoval se réfère également à Benoît comme à un saint éthiopien, un siècle avant le processus de béatification contesté dont il fit l'objet à Rome ${ }^{65}$. L'édition de 1627 du traité de Sandoval montre également une gravure de Benoît aux côtés de trois jésuites ainsi que l'extrait de Psaumes 87, Athiopia preveniet manuseius Deo. L'image de Benoît sur le frontispice fait office d'outil pédagogique visuel qui appuie l'argument du texte, qui le présente comme un saint éthiopien glorieusement restitué au christianisme, à qui Dieu a fait cadeau d'un don de vision et de pouvoirs miraculeux, et qui incarne la volonté de Dieu de restaurer l'Église d'Éthiopie ${ }^{66}$.

60. Ibidem, Livre I, Chap. XXXII, fols. 128v-130v.

61. Sur la biographie et la vénération dont fait l'objet Benoît de Palerme, voir Vincent BERNARD, "Saint Benoît de Palerme et l'Espagne", in Giovanna FIUME (éd.), Schiavitu, religione e libertà nel Mediterraneo tra medievo ed età moderna, Incontri Mediterranea, Cosenza, L. Pellegrini, 2008, p. 201-214; ID., "Le culte des saints noirs dans le monde ibérique», in David González RUIZ (éd.), Ritos y ceremonias en el mundo hispáno durante la Edad Moderna, Huelva, Universidad de Huelva-Centro de Estudios Rocieros, 2002, p. 121-132; ID., "Les confréries des noirs dans la péninsule Ibérique (XVe-XVIII" siècles)", in David GónZAlez CRUZ (éd.), Religiosidad y Costumbres populares en Iberoamérica, Huelva, 2000, p. 17-28; ID., "Les empires ibériques et les saints noirs: les exemples d'Elesban et d'Iphigénie", in Juan-Carlos Garavaglia, Jacques Poloni-Simard, Gilles Rivière (éd.), Au miroir de l'anthropologie historique, Mélanges offerts à Nathan Wachtel, Rennes, Presses universitaires de Rennes, 2013, p. 65-73.

62. Fray Antonio DAZA, O.F.M. (?-1640), Quarta parte de la Chronica general de Ntro. padre San Francisco y su apostolica orden / compuesta por fray Antonio Daça ... de su Orden..., Impresa en San Francisco de Valladolid, pour Juan Godines de Millis y Diego de Cordoua, 1611, Livre 4, p. 66-68, Fondo Antiguo Biblioteca Franciscana, Acervos Digitales, Universidad de las Américas Puebla, México, n: 000238239 , Digital Copy: http://catarina.udlap.mx/xmLibris/projects/biblioteca_franciscana/book?key=book_805a52. $x m l$. Pour une comparaison des hagiographies de saint Benoît de Palerme par Daza et Sandoval, voir L. BREwER-GARCÍA, "Hierarchy and Holiness...", art. cit.; E. K. Rowe, Black Saints..., op. cit. 63. A. SANDOval, Naturaleza, policia sagrada i profana..., op. cit., Livre I, Chap. XXXII, fols. $128 \mathrm{v}-130 \mathrm{v}$

64. Ibidem.

65. G. FiUme, «St. Bennedict the Moor», art. cit., p. 16-43.

66. Pour une autre analyse de ce même frontispice, voir L. BREWER-GARCÍA, "Imagined transformations...", art. cit. 
Il est important de noter que Sandoval ne considère pas impossible de ramener les Éthiopiens vers leur christianisme originel en Afrique même. Bien au contraire, le jésuite rend hommage aux conversions africaines, tout en considérant que trop d'obstacles à la propagation du salut existent sur le continent. Observons par exemple la comparaison effectuée par Sandoval entre l'authenticité du christianisme des Africains dans les royaumes du Kongo et d'Angola et celle des Africains de Guinée. Au Kongo, Sandoval estime possible de reconvertir avec succès les Éthiopiens et de ramener le christianisme au cœur de l'Afrique. La tâche exige le règne de dirigeants africains pleins de grandeur et de noblesse ${ }^{67}$. Sandoval décrit le Kongo comme un royaume chrétien glorieux qui reçut sa foi un siècle et demi auparavant, au contact des Portugais ${ }^{68}$. Il rend hommage au roi Pierre II du Kongo, connu sous le nom de Manikongo, qu'il présente comme très estimé à la fois de ses vassaux et des Européens, et que tous décrivent comme un monarque prudent, et un grand catholique. Sandoval observe que, depuis son couronnement, la foi du roi des Kongos jouit d'une renommée mondiale, notamment parce qu'il augmente le nombre de conversions au christianisme de ses sujets. Sandoval observe également que le roi surveille de près le bon comportement du clergé de son royaume, réprimandant publiquement tout prêtre dont la foi et les travaux marqueraient des signes de relâchement.

Sandoval est convaincu que le clergé africain est capable de développer les connaissances nécessaires pour faire recouvrer leur glorieux christianisme aux Éthiopiens déchus. Sa confiance est manifeste dans le passage élogieux qu'il consacre à ce clergé dans les différentes zones chrétiennes d'Afrique. Sandoval choisit par exemple de revenir sur la ville de S. Salvador au Kongo, ville qui peut se targuer de la présence d'une cathédrale, d'un évêque et de prébendiers et dignitaires dont beaucoup sont à la fois noirs et de "grands chrétiens", tout en observant que la majorité du clergé au Kongo est noire ${ }^{69}$. Sandoval décrit par ailleurs la présence à São Tomé de prébendiers noirs dont les compétences ecclésiastiques et l'érudition n'ont rien à envier aux clercs espagnols ${ }^{70}$. Ces descriptions indiquent bien que Sandoval ne considère pas que la couleur de peau ou l'origine africaine des prêtres constituent un obstacle au salut des âmes éthiopiennes.

Le problème avec l'établissement éventuel d'une Église noire élue en Afrique réside plutôt, selon Sandoval, dans l'existence en Afrique de conditions défavorables au salut des âmes, nonobstant le Kongo et les autres régions chrétiennes. Comparons maintenant le "glorieux» catholicisme dépeint cidessus à propos du Kongo avec la description qu'offre Sandoval du christianisme en Guinée, dans le port de Cacheu en particulier. Sandoval décrit

67. A. SANDoval, Naturaleza, policia sagrada i profana..., op. cit., Livre I, Chap. XV, «De los Etiopes de los reynos de Congo, y de Angola", fols. 55-59v.

68. Ibidem.

69. Ibidem.

70. Ibidem, Livre I, Chap. XV, fol. 55v. 
Cacheu comme «le port le plus important de toute la Guinée. Des bateaux viennent ici de Séville, du Portugal, de l'île de Santiago et de bien d'autres endroits encore pour faire la traite des esclaves et le commerce de bien d'autres biens». Il constate également que Cacheu comporte "un port de commerce, un marché, et une église, avec un prêtre nommé par le roi» ${ }^{71}$. Sandoval admet l'existence à Cacheu de chrétiens noirs ("de nombreuses personnes ont été baptisées ici avec succès", écrit-il) mais estime également que ces baptêmes devraient faire l'objet d'enquêtes méthodiques car «ces chrétiens noirs ont une connaissance très limitée du christianisme et interagissent avec des païens, ce qui veut dire qu'ils pourraient facilement revenir à des rites extérieurs à notre foi ${ }^{72}$. Le problème pour Sandoval n'est pas qu'à Cacheu (et dans d'autres villes portuaires) les hommes et les femmes noirs soient incapables d'être ramenés au christianisme, mais plutôt que les baptêmes dans la région sont généralement vains car ils ne comportent pas une direction spirituelle, des soins ou une transmission religieuse appropriés :

"On peut en inférer que les prêtres et les propriétaires commettent de graves péchés en Guinée, sur les bateaux et dans les autres endroits où ils célèbrent des baptêmes. Ils commettent un sacrilège en administrant un sacrement qui est moralement nul, à l'évidence, douteux, et sans aucun doute privé de son effet principal, c'est-à-dire la grâce, car les esclaves adultes n'y sont pas préparés en ayant acquis la foi et la repentance nécessaires $»^{73}$.

En l'état actuel des choses, la majorité des conversions en Afrique impliquent des mauvaises pratiques, manquent de sincérité et sont rarement bien comprises par ceux qui reçoivent le sacrement du baptême. Malgré l'exemple du Kongo, Sandoval reste donc dans l'ensemble très sceptique quant à la possibilité d'une juste restauration de l'âme des Éthiopiens en Afrique. Il est convaincu que cette opération ne peut être menée correctement que par des jésuites établis dans le Nouveau Monde.

Le salut de l'âme des Éthiopiens ne peut s'effectuer que si l'Afrique est purgée de ses habitants afin qu'ils peuplent le Nouveau Monde, et qu'une Église noire élue soit établie dans les ports des Antilles espagnoles. C'est ce qui transparaît non seulement dans l'hommage appuyé que le jésuite rend à saint Benoît le More en sa qualité exemplaire d'Éthiopien restauré dans sa foi originelle, mais également dans la copie qu'il fait de la description donnée par Frère Daza d'une image de Benoît le More dans les Antilles espagnoles. Ainsi, Sandoval affirme avec enthousiasme que Dieu a choisi de poursuivre les miracles de Benoît après sa mort en faisant apparaître son image dans le couvent de San Francisco, dans la ville de Los Ángeles [Puebla] en Nouvelle-Espagne (aujourd'hui, le Mexique) ${ }^{74}$. Sandoval se sert de l'apparition de ce tableau en Nouvelle-Espagne, si loin du lieu de la naissance italienne du saint noir, pour

71. Ibidem, Livre I, Chap. XI, fols. 38r-41.

72. Ibidem.

73. Ibidem, Livre III, Chap. V. fols. 249v-257.

74. Ibidem, Livre I, Chap. XXXII, fol. 130v. 
étayer sa vision du Nouveau Monde comme lieu idéal pour la restauration d'une Église élue noire, vision qui va évidemment de pair avec sa fonction de missionnaire à Carthagène des Indes.

De cette vision découle la justification théologique de l'asservissement des Africains noirs. Pour Sandoval, si l'on est déjà chrétien mais que l'on est une âme perdue ou corrompue, l'esclavage se justifie. Il l'explique: «le débat parmi les lettrés sur la justification du commerce difficile et ardu de l'esclavage me rend perplexe depuis longtemps ${ }^{75}$. Sandoval raconte que différents marchands d'esclaves sont venus le trouver à Carthagène des Indes pour chercher ses lumières sur la légitimité et la moralité de leur commerce, lui confiant ne pas savoir si les Africains qu'ils ont transportés ont été asservis justement ou non ${ }^{76}$. Sandoval décrit "un capitaine, propriétaire de bateaux négriers qui avait effectué de nombreux voyages à [São Tome]" pour son plus grand enrichissement, mais qui se rendait compte que "sa conscience portait le lourd fardeau du doute quant à la manière dont ces esclaves étaient arrivés entre ses mains ${ }^{77}$. Le capitaine rapporte à Sandoval qu'il est gêné par la manière dont "un de leurs rois a emprisonné toute personne qui mettait le roi en colère afin de les vendre en esclavage aux Espagnols ${ }^{78}$. Le jésuite raconte également que les capitaines de deux navires transportant des personnes réduites en esclavage arrivés d'Angola l'ont consulté à propos de la moralité de la traite des esclaves ${ }^{79}$. L'un d'eux se confie à lui dans les termes suivants :

«Père, je vais en Angola pour acheter des Noirs. C'est une traversée coûteuse et dangereuse. Quand je repars, après avoir dépensé beaucoup d'argent pour acheter les esclaves, je me sens coupable. Je me demande si je suis satisfait de la manière dont on justifie l'esclavage. Et si je les emmenais vivre le restant de leurs jours sur des terres chrétiennes mais qu'ils ne devenaient jamais des chrétiens?» 80

En réponse à une demande de Sandoval, un jésuite de Luanda nommé Luís Brandão lui aurait assuré qu'il n'avait nul besoin de s'inquiéter de savoir si la traite était juste ou non car «des hommes sages à la conscience claire ne jugent pas l'esclavage très répréhensible [...], des évêques à São Tome, au Cap-Vert, et ici à Luanda, des hommes sages et vertueux, ne protestent jamais contre l'esclavage" 81 . Brandão rappelle également que des pères jésuites installés depuis quarante ans dans la région, ont eux-mêmes acheté des esclaves «sans ressentir

75. Ibidem, Livre I, Chap. XVII, De la Esclavitud de estos negros de Guinea, y demás puertos, y hablando en general, fols. 65-70v. Voir aussi Eduardo CÁRDENAS, "La ética cristiana y la esclavitud de los negros; Elementos históricos para el planteamiento de un problema", Theologica Xaveriana, 55, 1980, p. 227-257.

76. A. SANDOVAL, Naturaleza, policia sagrada i profana..., op. cit., Livre I, Chap. XVII, De la Esclavitud de estos negros de Guinea, y demás puertos, y hablando en general, fols. 65-70v.

77. Ibidem.

78. Ibidem, Livre I, Chap. XVII, De la Esclavitud de estos negros de Guinea, y demás puertos, y hablando en general, fols. $65-70 \mathrm{v}$.

79. Ibidem.

80. Ibidem.

81. Ibidem. 
la moindre culpabilité» ${ }^{82}$. Brandão rassure Sandoval en affirmant que l'objectif supérieur de sauver des âmes justifie à lui seul la poursuite de la traite, même si cela veut dire que quelques esclaves ont été asservis injustement "car tant d'âmes ont été sauvées par l'esclavage, que nous servons mieux Dieu en sauvant tous ceux qui ont été asservis légitimement plutôt que de n'en sauver aucun au nom de quelques-uns qui auraient été asservis injustement ${ }^{83}$. Sandoval réitère cet argument dans sa réponse à l'un des capitaines inquiets qui avait cherché son conseil au sujet de la moralité de la traite d'esclave à Carthagène des Indes : "Votre commerce n'est pas immoral, et vous ne serez pas puni, parce que vous dites que vous amenez les Noirs ici de bonne foi et pour une bonne raison ${ }^{84}$.

Ainsi, Sandoval essaie de "prouver» que l'Éthiopie a été la première Église à connaître une histoire chrétienne riche et glorieuse, tout en établissant que les âmes éthiopiennes ont été corrompues en Afrique à travers des descriptions détaillées de la barbarie censée régner dans plusieurs régions du continent ${ }^{85}$. En assimilant tous les hommes et les femmes à la peau foncée à des Éthiopiens, en documentant les difficultés attenant à une conversion sincère au christianisme en Afrique et, enfin, en démontrant de quelle manière les femmes et les hommes noirs qui ont été correctement baptisés et éduqués ont été rendus à leur ancienne gloire de chrétiens éthiopiens en qualité de saints éthiopiens hors d'Afrique, Sandoval défend sa thèse de l'asservissement des Noirs comme moyen de leur rendre, par le baptême et la direction spirituelle, leur christianisme historique. Cette transformation qui doit, selon lui, s'opérer dans le Nouveau-Monde, faisait des Antilles espagnoles le site d'une Église noire élue, argument-clé chez Sandoval de la justification théologique de l'asservissement des Noirs africains.

Sandoval n'est pas le seul à promouvoir ce type de raisonnement théologique: il fait partie d'une cohorte de missionnaires de la même période qui mélangent les légendes sur les chrétiens d'Éthiopie et les font porter sur tous les Noirs d'Afrique sans tenir compte de leur origine spécifique, et qui se servent de ces théories pour justifier l'asservissement à grande échelle des Africains. Son disciple Pedro de Claver (1580-1654), dont le mandat à Carthagène débute en 1616, deviendra célèbre pour avoir prétendu, non sans exagération, avoir baptisé tout au long de sa carrière à Carthagène plus de 300000 Africains, hommes et femmes, ce qui lui aurait valu la devise "semper aethiopum servus", «esclave des Éthiopiens pour toujours " ${ }^{86}$. Le jésuite portugais António Vieira (1608-1697), établi à Bahia, considérait la découverte de la Haute-Guinée par le Portugal au XVI ${ }^{\mathrm{e}}$ siècle comme la réalisation des prophéties de l'Ancien Testament au sujet du salut des âmes africaines décrites dans les psaumes 71

82. Ibidem

83. Ibidem.

84. Ibidem.

85. A. SANDOVAL, Naturaleza, policia sagrada i profana..., op. cit., Livres I et II.

86. Sanctissimo ac Beatissimo Domino Nostro, Domino Clementi Divina Provida. Papae Decimo, salutem et apostolicam dilectionem [manuscrit], 1676, Biblioteca Nacional de Colombia, RM 281 ; Proceso de beatificación y canonización de san Pedro Claver, op. cit. 
et $77^{87}$. Comme Sandoval, Vieira situe l'origine des esclaves africain en Éthiopie: «Oh, si les Noirs pris dans les denses forêts de leur Éthiopie et amenés au Brésil savaient ce qu'ils doivent à Dieu et à la très sainte Marie Mère de Dieu en ce qui peut ressembler à l'exil, la captivité et la disgrâce mais n'est rien d'autre qu'un miracle, un immense miracle!» 88 Selon cette lecture, le salut de l'âme des Africains ne peut passer que par l'esclavage dans le Nouveau Monde. Comme certains de ses contemporains, Sandoval ne considère donc pas la peau noire comme l'indice d'un sang irrémédiablement entaché et de l'appartenance à un lignage impur. Au contraire, les Africains noirs représentent la plus ancienne nation chrétienne, que les jésuites vont aider à retrouver son ancienne gloire, mais en Amérique plutôt qu'en Afrique, et par le biais de l'esclavage.

\section{Campagne transatlantique pour les baptêmes}

L'argument de Sandoval pour justifier l'esclavage des Noirs d'Afrique explique pourquoi ses disciples à Carthagène des Indes se préoccupaient autant des bonnes conditions de baptêmes des esclaves. Sandoval consacre la majeure partie de son traité à la délicate question de la pratique, fort répandue, des baptêmes non réglementaires célébrés pendant la traite des esclaves, et propose des solutions pour y remédier. Sandoval est convaincu que le rite suivi lors de ces baptêmes est tellement incorrect que ceux-ci sont frappés de nullité. Or, en l'absence d'un baptême pratiqué en bonne et due forme, les Africains ne pourront jamais renouer avec leur passé glorieux d'Éthiopiens originels et, par extension, tout le système de justification de l'esclavage s'effondre. Il est donc question de contrôler la qualité du rite baptismal, ce qui finit par obséder Sandoval au point qu'il cherche non seulement à s'assurer de l'accueil que réservent les prêtres aux Africains captifs à leur arrivée dans les ports des Antilles, mais qu'il lance également une campagne à grande échelle destinée à alerter les autorités royales et religieuses dans l'ensemble du monde ibérique sur la nécessité de corriger ces baptêmes incorrects. C'est également ce à quoi il consacre l'essentiel de son traité.

Les historiens estiment qu'un minimum de 487 navires négriers sont «arrivés à Carthagène entre 1573 et 1640, débarquant au moins 78453 Africains esclaves dans la ville et les ports voisins ${ }^{89}$. La plupart de ces personnes réduites en esclavage venaient de Haute Guinée et d'Angola ${ }^{90}$. Les Africains capturés

87. Père Antônio VIEIRA, "Sermão XIV», Sermões. 5 vols, Porto, 1993, V.4, P.P. p. 733-769. Pour une analyse de Vieira, voir Luiz Felipe DE AlEnCASTRO, "Portuguese missionaries and early modern antislavery and proslavery thought", in Josep M. FRADERA, Christopher SCHMIDT-NOwARA $\dagger$ (éd.), Slavery And Antislavery In Spain's Atlantic Empire, New York, Berghahn Books, 2013; L.F. De Alencastro, The Trade in the Living; The Formation of Brazil in the South Atlantic, Sixteenth to Seventeenth Centuries, New York, State University of New York Press, 2018.

88. Père A. Vieira, Sermões..., op. cit. Voir également L.F. De Alencastro, The Trade in the Living..., op. cit.

89. A. Borucki, D. Eltis, D. WheAt, "Atlantic History and the Slave Trade», art. cit.

90. D. WheAT, "The First Great Waves: African Provenance Zones for the Transatlantic Slave Trade to Cartagena", art. cit. 
et asservis qui survivent à l'abomination de leur arrachement hors d'Afrique (enchaînés sous le pont de navires qui traversent l'Atlantique) et qui débarquent au port de commerce de Carthagène des Indes au début du XVII ${ }^{\mathrm{e}}$ siècle se retrouvent en général sur des vaisseaux qui mouillent pendant des jours, voire des semaines, dans les baies entourant la ville, selon les modalités définies par les autorités portuaires pour tenter de contenir le risque de contagion par d'éventuelles maladies transportées sur les bateaux. C'est de cet intervalle que profitent les deux prêtres jésuites, Alonso de Sandoval et Pedro de Claver, ou leur bataillon d'interprètes africains (esclaves ou émancipés), pour embarquer sur des petites chaloupes qui les mènent aux captifs enchaînés sur les bateaux amarrés ${ }^{91}$. L'objectif de ces rencontres est d'évaluer minutieusement l'étendue des connaissances religieuses des Africains. C'est en tout cas ce qu'affirment les jésuites dans l'abondante correspondance qu'ils font parvenir à Rome au début du $\mathrm{XVII}^{\mathrm{e}}$ siècle $^{92}$. Dans ces épîtres transatlantiques, qui ont fait l'objet d'une patiente exploration par María Cristina Navarrete, les prêtres jésuites de Carthagène aiment à se présenter comme le moteur des efforts baptismaux à destination des Africains captifs dans le port, l'un des plus importants du début du XVII ${ }^{\mathrm{e}}$ siècle en termes de volume de fret dans la Caraïbe espagnole ${ }^{93}$. En essayant de rencontrer systématiquement les nouveaux arrivants, ils cherchent à déterminer les besoins spirituels de ces Africains dénutris et maltraités, et à savoir en particulier s'ils ont été correctement baptisés en Afrique. De la même manière, les interprètes noirs de Carthagène, esclaves ou libres, qui témoignent lors du procès de béatification de Pedro Claver à la fin du XVII ${ }^{\mathrm{e}}$ siècle, déclarent avoir accompagné ce dernier sur les bateaux jusqu'à ce qu'il devienne trop faible, après quoi ils s'y rendaient seuls pendant que Claver attendait impatiemment leur rapport sur les besoins spirituels des esclaves fraîchement arrivés ${ }^{94}$. Claver leur demandait d'accueillir les captifs avec des biscuits, des bananes plantains, des meringues, des citrons verts et du tabac, et d'enquêter minutieusement pour déterminer si chaque esclave avait été correctement baptisé ${ }^{95}$. Dans les informations

91. Sanctissimo ac Beatissimo Domino Nostro, Domino Clementi Divina Provida. Papae Decimo, salutem et apostolicam dilectionem [manuscrito], 1676, Biblioteca Nacional de Colombia, RM 281; Proceso de beatificación, op. cit., "Administración del Bautismo", p. 84-124.

92. Sanctissimo ac Beatissimo Domino Nostro..., op. cit., "Administración del Bautismo", p. 84-124; María Cristina NAVARRETE PELAÉZ, «Las cartas Annuas jesuitas; Y la representación de los etíopes en el siglo XVII", in M. EugEnia, C. MALdonAdo (éd.), Genealogias de la diferencia..., op. cit., p. 22-57; L. BREWER-GARCÍA, "Imagined transformations...», art. cit.

93. M. C. Navarrete PelaÉz, "Las cartas Annuas jesuitas», art. cit. Voir aussi Andrea GUERRERO MOSQUERA, «Misiones, misioneros y bautizos a través del atlántico: evangelización en Cartagena de Indias y en los reinos del Kongo y Ngola. Siglo XVII", Revista Memoria y Sociedad, 2014, 18-37, p. 21-25, ainsi que EAD., "Los Jesuitas en Cartagena de Indias y la evangelización de africanos. Una Aproximación", Revista de Humanidades y Educación, 2018, 52, p. 13-20.

94. Proceso de beatificación y canonización de san Pedro Claver, op. cit., p. 84-124.

95. Pour une analyse du rôle des interprètes africains asservis à Carthagène, L. BREWER-GARCÍA, "Imagined Transformations", art. cit.; EAD., Beyond Babel. Translations of Blackness in Colonial Peru and New Granada, Cambridge, Cambridge University Press, 2020; A. Guerrero MosquerA, "Misiones, misioneros y bautizos", art. cit., p. 25-28 et EAD., "Los Jesuitas en Cartagena», art. cit., p. 21-24. 
fournies pour la béatification de Claver, ces mêmes interprètes et d'autres prêtres jésuites décrivent comment les esclaves africains ont été débarqués des bateaux à Carthagène pour être emprisonnés dans des enclos près du port pendant la durée des opérations de marchandisation, de classification, de taxation, d'examen et de vente auxquelles leurs corps sont soumis ${ }^{96}$. C'est le moment que choisit Claver pour célébrer des baptêmes sophistiqués au cours desquels on l'assure, par le biais des interprètes, que ses ouailles captives comprennent bien la signification du baptême et sont mues par le désir sincère de devenir chrétiens ${ }^{97}$.

Ce rituel d'accueil des esclaves africains est une réponse aux inquiétudes d'Alonso de Sandoval, qui craint que prêtres et marchands d'esclaves ne pratiquent à grande échelle des baptêmes incorrects en Afrique et sur les bateaux. Cette crainte renforce l'importance que Sandoval accorde aux prêtres qui officient dans les principaux ports de la traite, tels que «Lisbonne, Séville, Baïa, Pernambuco, Rio de Janeiro, Buenos Aires, San Iuan de Lua, Puertorico, Carthagène, Panama et Lima». Il estime que ces prêtres ont l'obligation de déterminer si des baptêmes incorrects ont eu lieu et «d'examiner, instruire religieusement et baptiser les Noirs qui portent des noms chrétiens et ne sont d'ordinaire pas chrétiens $\|^{98}$. Sandoval enjoint les prêtres d'accueillir les bateaux quand ils arrivent, avant que «[les marchands d'esclaves] ne commencent à vendre et disperser [les esclaves] dans différents lieux ${ }^{99}$. Il affirme que cette opération est absolument nécessaire car les marchands et les propriétaires d'esclaves dans d'autres régions des Antilles ont tendance à tenir pour acquis le baptême de leurs esclaves, persuadés que «puisque [les Noirs] sont passés par le port, ils ont

96. Sur la marchandisation, la classification, la taxation, l'examen et la vente d'esclaves africains à Carthagène au début du XVII ${ }^{\mathrm{e}}$ siècle, A. BORUCKI, D. ElTIS, D. WHEAT, "Atlantic History and the Slave Trade", art. cit.; Jane LANDERS, "The African Landscape of $17^{\text {th }}$ Century Cartagena and its Hinterlands", in Jorge CAÑIZARES-EZguerRA, James SidBury, Matt D. ChILdS (éd.), The Black Urban Atlantic in the Age of the Slave Trade (The Early Modern Americas), Philadelphie, University of Pennsylvania Press, 2013, p. 147-162; J. LANDERS, "Cimarrón and Citizen; African Ethnicity, Corporate Identity and the Evolution of Free Black Towns in the Spanish Circum-Caribbean", in Jane G. LANDERs, Barry M. Robinson (éd.), Slaves, Subjects, and Subversives: Blacks in colonial Latin America, Albuquerque, University of New Mexico Press, 2006; M. C NAVArRete PelÁEZ, "Consideraciones en torno a la esclavitud de los Etíopes y la operatividad de la ley, siglos XVI y XVII", Historia y espacio, 27, 2006, p. 1-23; EAD, Génesis y desarrollo de la esclavitud en Colombia siglos XVI y XVII, Meléndez, Universidad del Valle, 2005; EAD, «Kings, queens and captains: leaders of the Palenques of Sierras de María during the XVI and XVII Centuries", Fronteras de la Historia, 20-2, 2015, p. 44-62; EAD, "Las cartas Annuas jesuitas; Y la representación de los etíopes en el siglo XVII", in Genealogias de la diferencia..., op. cit. p. 22-57; Linda A. Newson et Susie Minchin, From Capture to Sale, The Portuguese Slave Trade to Spanish South America in the Early Seventeenth Century, Leyde, Brill, 2007; Rachel Sarah O'Toole, Bound Lives Africans, Indians, and the Making of Race in Colonial Peru, Pittsburgh, University of Pittsburgh Press, 2007; M. Olsen, Slavery and Salvation..., op. cit.; Antonino VidAL OrTEGA, "El mundo urbano de negros y mulatos en Cartagena de Indias entre 1580-1640", Historia Caribe, V-2, 2000, p. 87-102; ID., Cartagena y la región histórica del Caribe. 1580-1640, Escuela de Estudios Hispanoamericanos (CSIC), Universidad de Sevilla, 2002.

97. Sanctissimo ac Beatissimo Domino Nostro..., op. cit., "Administración del Bautismo", p. 84-124; M. C. NAvarrete PelÁEZ, "Las cartas Annuas jesuitas», art. cit. Voir aussi L. Brewer-García, Beyond Babel..., op. cit.

98. A. SANDOVAL, Naturaleza, policia sagrada i profana, op. cit., Livre III, chap. XIII, fols. 286v-287r. 99. Ibidem. 
déjà été baptisés ${ }^{100}$. Sandoval précise que ce sont les prêtres qui officient dans les ports qui doivent déterminer, dès l'arrivée des bateaux, si les esclaves noirs «appartiennent à Jésus Christ et son Église, et dans le cas contraire, s'assurer qu'ils le fassent ${ }^{101}$. Dans ce but, les jésuites de Carthagène forment un groupe d'Africains, esclaves ou émancipés, qui deviennent des interprètes à même de les assister pour communiquer avec des esclaves aux profils linguistiques variés, dans l'idée qu'«en [leur] parlant par le biais de leur propre langue et des interprètes, on peut les juger en fonction des réponses aux questions qui leur sont posées ${ }^{102}$.

Inquiet du nombre de baptêmes incorrects d'esclaves débarqués à Carthagène, Sandoval entame une campagne épistolaire transatlantique avec les autorités royales et religieuses dans tout le monde ibérique (y compris avec les prêtres en Afrique) afin de leur faire prendre conscience des problèmes théologiques qui surviennent quand des Noirs, captifs ou émancipés, vivent en chrétiens alors qu'ils n'ont pas été correctement baptisés ${ }^{103}$. Fort des entretiens détaillés et de son expérience directe de missionnaire à Carthagène des Indes, Sandoval décrit dans ses missives la manière dont les marchands et les propriétaires d'esclaves, les prêtres et les missionnaires échouent à assurer que les esclaves sont correctement baptisés. Ainsi dans une de ces lettres, Sandoval raconte comment il a administré l'extrême-onction à une Noire libre propriétaire de maisons et d'esclaves à Carthagène, avant de découvrir que bien qu'elle vécût en chrétienne parmi les chrétiens, elle n'avait pas été correctement baptisée ${ }^{104}$. Sandoval estime que ces baptêmes incorrects ou nuls posent un problème théologique et que l'Église doit se préoccuper des personnes noires, esclaves ou libres, qui reçoivent un baptême incorrect qui entraînent la nullité d'autres sacrements, comme le mariage.

Sandoval explique que de nombreux nouveaux baptêmes, en particulier pour les Noirs qui vivent en chrétiens et ont déjà reçu d'autres sacrements, doivent être administrés en secret. En effet, cette pratique, si elle était rendue publique, pourrait s'avérer terriblement dommageable pour l'honneur des nouveaux baptisés, perçus alors comme ayant un sang impur et ayant vécu en chrétiens (et reçu d'autres sacrements) de manière frauduleuse ${ }^{105}$. Ce souci de la correction de la procédure fait écho aux craintes qui font alors rage en Castille à propos de faux chrétiens dont la foi publique masquerait l'adhésion à une

100. Ibidem.

101. Ibidem.

102. Ibidem, Livre III, Chap. VII, fol. 261.

103. Voir par exemple, Ibidem, Livre III, Chap. XXII, fols 326v-334v. Berta Ares QUEIJA, «La cuestión del bautismo de los negros en el siglo XVII: la proyección de un debate americano", non-publié (http://digital.csic.es/bitstream/10261/57537/1/Binder1.pdf).

104. Lettre d'Alonso de Sandoval citée dans Hélène VignAux, L'Église et les Noirs..., op. cit., "Le rôle primordial des Jésuites dans l'évangélisation des Noirs de Nouvelle Grenade", p. 327-504.

105. Ruth PIKE, Linajudos and Conversos in Seville. Greed and Prejudice in Sixteenth-and Seventeenth-Century Spain, New York, Peter Lang, 2000; Irene SilverblatT, "New Christians and New World Fears in Seventeenth-Century Peru ", in Brian Keith Axel (éd.), From the Margins. Historical Anthropology and Its Futures, Durham, Duke University Press, 2002, p. 95-121. 
autre religion en privé. Cependant, la recommandation de Sandoval pour que ces nouveaux baptêmes soient célébrés dans la clandestinité indique également qu'il considère que l'authenticité du baptême détermine bien davantage l'honneur d'une personne que sa couleur de peau, position qui rappelle l'importance attribuée au baptême par les officiers royaux de la Casa de la Contratación (Chambre de Commerce) chargés d'attribuer ou non les permis de voyager depuis la Castille jusqu'aux Antilles espagnoles aux hommes et femmes noirs libres au XVI ${ }^{\mathrm{e}}$ et au début du XVII ${ }^{\mathrm{e}}$ siècle: les dépositions de témoins versées au dossier des demandeurs noirs attestaient souvent de l'authenticité du baptême et du christianisme de ces derniers ${ }^{106}$.

Conséquence de la campagne épistolaire de Sandoval, certains évêques ordonnent l'organisation en masse de nouveaux baptêmes pour les populations noires de certains centres urbains, comme Séville et Lima. Dans son traité, Sandoval raconte que ses efforts ont conduit Pedro de Castro y Quiñones, archevêque de Séville, à commanditer le 20 février 1614 une enquête secrète pour déterminer si "plus de six mille adultes» noirs, résidents dans l'archevêché de Séville et arrivés des "ports de Guinée et d'autres parties d'Afrique», avaient été correctement baptisés ${ }^{107}$. Toute personne reconnue à Séville comme ayant reçu un baptême nul ou inapproprié devait être rebaptisée. Sandoval souligne le caractère sensible d'une telle enquête:

«Il est d'une importance suprême que [cette enquête] soit menée dans le plus grand secret et avec la plus grande prudence, en particulier l'examen des ladinos [noirs]... [qui], après avoir été si longtemps considérés comme chrétiens et pour ne pas admettre cette abomination, nient la vérité autant qu'ils le peuvent» ${ }^{108}$.

Il rapporte que l'archevêque de Séville a autorisé des hommes et femmes noirs à être rebaptisés en secret s'ils le souhaitaient. C'est ainsi que l'école jésuite de San Hermenegildo à Séville administre tous les nouveaux baptêmes en secret quand l'opération est jugée nécessaire. L'instruction détaille également la sensibilité qu'il convient de montrer envers les Noirs libres, ladinos, qui vivent en chrétiens depuis longtemps et ont reçu d'autres sacrements comme la confirmation ou le mariage sans toutefois avoir été correctement baptisés. Suivant les conseils de Sandoval, l'archevêque réclame l'annulation du mariage de ces personnes, qui doivent alors se remarier au plus vite après leur second baptême afin d'éviter de vivre dans le péché ${ }^{109}$.

Sandoval affirme que l'enquête de Séville est une vraie réussite, empreinte d'une indiscutable crédibilité, et qui produit «tant de gloires et sauve tant

106. Chloe L. IRETON, "“They are Blacks of the Caste of Black Christians”: Old Christian Black Blood in the Sixteenth- and early seventeenth-century Iberian Atlantic", Hispanic American Historical Review, 97-4, 2017, p. 579-612.

107. A. SANDOval, Naturaleza, policia sagrada i profana, op. cit., Livre III, Chap. XXII, fols 326v-334v.

108. Ibidem, Livre III, Chap. XXII, fols 326v-334v.

109. Ibidem. 
d'âmes qui risquaient la condamnation éternelle» qu'elle devrait devenir la norme pour toutes les paroisses d'Espagne et des Antilles ${ }^{110}$. C'est d'ailleurs, affirme Sandoval, ce que réclame le pape ${ }^{111}$. À Carthagène, en effet, un prêtre jésuite rapporte que Pedro de Claver s'est servi du même modèle d'enquête pour ses rites baptismaux, sur les précisions de l'archevêque de Séville qui elles-mêmes faisaient écho aux conseils initiaux prodigués plus tôt par Sandoval dans sa correspondance ${ }^{112}$. Parmi les témoignages recueillis dans le cadre de la béatification de Pedro de Claver en 1696, un prêtre jésuite de Carthagène, Nicolas González, indique que, dans le cadre de l'instruction et de la catéchèse dispensée aux "Noirs", Claver suivait à la lettre "les instructions que l'archevêque de Séville, Don Pedro de Castro y Quiñones, a mises au point en consultation avec les principaux théologiens de l'archevêché", afin de "préparer le baptême des Noirs et des Maures turcs et des individus issus de toute autre nation vivant dans l'archevêché "113.

Les échanges transatlantiques menés par Sandoval à propos des bonnes pratiques baptismales pour les Éthiopiens, d'abord avec des missionnaires établis en Afrique puis avec des archevêques de Rome et des quatre coins du monde ibérique, ainsi que l'enquête menée par l'archevêque de Séville sur le besoin de faire rebaptiser les Noirs et la répétition des mêmes consignes, de Séville à Carthagène, à travers Pedro de Claver et ses interprètes africains soulignent l'importance, des deux côtés de l'Atlantique, de la perception de l'Éthiopie à cette période. L'obsession de Sandoval pour la correction des opérations de baptême des Africains réduits en esclavage à Carthagène des Indes au début du XVII ${ }^{\mathrm{e}}$ siècle et sa campagne transatlantique pour corriger les baptêmes illégitimes d'Africains noirs dans le monde ibérique sont les derniers éléments de son système de justification théologique de l'esclavage: afin qu'une Église noire élue puisse voir le jour, il est nécessaire que les Africains reçoivent un baptême légitime et une instruction religieuse correcte.

Relire les inquiétudes de Sandoval sur le baptême des femmes et des hommes noirs au prisme de son engagement visant à restaurer les âmes éthiopiennes révèle l'importance de l'imaginaire de l'Éthiopie auprès des instances royales et religieuses et chez les missionnaires du début du XVII ${ }^{\mathrm{e}}$ siècle. Il est ici question de la création d'une légende, celle d'une Église éthiopienne ancienne et glorieuse, choisie par Dieu pour être la première Église chrétienne, et de la manière dont cette légende a été instrumentalisée par un jésuite pour justifier l'asservissement en masse de tous les Africains et leur arrachement à l'Afrique

110. Ibidem.

111. Ibidem.

112. Proceso de beatificación y canonización de san Pedro Claver, op. cit., p. 91.

113. Ibidem, p. 91. 
au nom de l'établissement d'une Église noire élue dans le Nouveau Monde. En me focalisant ici sur l'Éthiopie, je ne prétends pas que ce pays ait été le cœur des discussions sur la noirceur de peau au XVI ${ }^{\mathrm{e}}$ et au début du XVII ${ }^{\mathrm{e}}$ siècle, mais je veux plutôt mettre en avant le fait que l'idée, omniprésente dans les recherches actuelles, selon laquelle les discours sur la pureté du sang dans le monde ibérique excluaient unanimement les Africains noirs de l'appartenance à une vieille lignée chrétienne, a produit des lacunes historiographiques considérables sur les divers débats qui, aux XVI ${ }^{\mathrm{e}}-\mathrm{XVII}{ }^{\mathrm{e}}$ siècles, avaient cours sur le christianisme africain et la signification de la couleur noire. Elle a occulté la façon dont des théologiens comme Sandoval ont justifié l'asservissement massif des hommes et des femmes noirs en faisant de l'Éthiopie le cœur historique des origines chrétiennes des Africains noirs.

Les différentes manières dont les auteurs du XVI ${ }^{\mathrm{e}}$ et du début du $\mathrm{XVII}^{\mathrm{e}}$ siècle se sont servi du christianisme éthiopien mettent en lumière un pluralisme important dans les idées de l'époque sur la couleur noire, la lignée religieuse, la religion et la finalité de la traite des Noirs. Ces usages révèlent une préoccupation centrale pour la lignée religieuse, qui n'est pas nécessairement liée à la couleur de peau, mais tient davantage aux preuves de pureté religieuse et de proximité avec la première Église chrétienne. Ainsi, à la fin du $\mathrm{XVII}^{\mathrm{e}}$ siècle, un frère capucin basé aux Antilles nommé Francisco José de Jaca s'appuie sur les mêmes extraits bibliques que Sandoval ("Etiopía extienda sus manos a dios") pour démontrer, à l'inverse du jésuite, que l'asservissement des Africains est injuste ${ }^{114}$.

Ces discours théologiques influencent la manière dont nous lisons l'histoire des conversions qui ont eu lieu dans les villes portuaires du monde atlantique ibérique, et affectent potentiellement notre compréhension des débats théologiques auxquels les Africains, esclaves ou libres, ont pu assister ou participer avec les prêtres. La Compagnie jésuite de Carthagène des Indes se considérait à l'époque comme un instrument central de l'opération de restauration d'une Église éthiopienne élue; cet objectif colore nécessairement le regard que nous pouvons porter sur l'histoire de l'activité jésuite à Carthagène. Bien que la Compagnie de Jésus ait été de taille relativement modeste au début du XVII ${ }^{\mathrm{e}}$ siècle, ne comptant que six pères et cinq frères en 1611, cette poignée de religieux a occupé une place absolument centrale au cœur de la vie pastorale et religieuse des Africains noirs, esclaves ou libres,

114. Francisco José DE JACA, «Resolución sobre la libertad de los negros y sus originarios en el estado de paganos y después ya cristianos ", Archivo General De Indias, Séville, Audiencia De Santo Domingo, Legajo 527, cité dans José Tomas López GARCÍA, Dos Defensores De Los Esclavos Negros En El Siglo XVII (Francisco fosé De faca Y Epifanio De Moirans), Biblioteca Corpozulia, Maracaibo, Universidad Católica Andrés Bello, Caracas, 1982, p. 160. Voir également F. J. DE JACA, Resolución Sobre La Libertad De Los Negros Y Sus Originarios, En Estado De Paganos Y Después Ya Cristianos: La Primera Condena De La Esclavitud En El Pensamiento Hispano, éd. Miguel Anxo Pena GonZÁlez, Madrid, Editorial CSIC-CSIC Press, 2002 [1682]. 
qui résidaient dans la ville portuaire ${ }^{115}$. Dans un tel contexte de proximité physique (et pastorale) entre jésuites et Africains noirs de Carthagène, il semble essentiel de s'interroger sur l'étendue de la circulation des idées de Sandoval sur le christianisme éthiopien et la restauration d'une Église éthiopienne à Carthagène parmi les Noirs de la ville, et également de s'interroger sur la manière dont les Noirs esclaves et émancipés du port se sont appropriés, avec des objectifs largement différents de ceux des jésuites, ces récits d'appartenance à un héritage chrétien ancien.

En d'autres termes, l'existence même du discours d'Alonso de Sandoval sur les chrétiens éthiopiens met au jour la possibilité, dans les premiers temps de l'empire ibérique, de construire une histoire des origines des Africains noirs qui ne soit pas fondée sur la notion d'un sang irrémédiablement entaché qui condamnerait les Africains perpétuellement à la marge du monde catholique. Ce discours alternatif a pris une importance toute particulière lorsque les sujets noirs, esclaves ou libres, du monde colonial ibérique ont commencé à mobiliser certains récits qui lui étaient attachés, disponibles dans certains espaces particuliers, comme la vénération largement répandue de saints noirs tel Benoît de Palerme dans les confraternités religieuses. Il a aussi joué un rôle non négligeable lorsqu'ils ont développé des discours sur l'illégitimité de l'esclavage fondés sur les origines chrétiennes des Africains noirs devant les tribunaux castillans pour réclamer leur liberté ou bien lorsque des sujets coloniaux noirs se sont revendiqués comme Vieux chrétiens à divers moments de l'histoire du monde ibérique. Il est donc nécessaire de comprendre les discours proposés par des théologiens de premier plan comme Alonso de Sandoval, en particulier en raison de sa proximité spatiale et pastorale avec les populations noires du port de Carthagène des Indes, pour retracer les liens possibles entre ces débats théologiques sur la couleur noire et l'Afrique avec la production intellectuelle des populations noires dans diverses situations locales.

Chloe L. IRETON Department of History University College London Gower Street Londres WC1E 6BT c.ireton@ucl.ac.uk

Traduit de l'anglais (États-Unis) par Élise Trogrlic. 


\section{Résumé/Abstract}

Chloe L. IRETON

L'imaginaire éthiopien dans le premier monde hispanique: esclavage et baptême dans le Catéchisme évangélique de Sandoval

Parmi les nombreuses "vérités» répandues dans la recherche sur la couleur de peau noire dans le monde ibérique du XVI ${ }^{\mathrm{e}}$ et du début du XVII ${ }^{\mathrm{e}}$ siècle, on retrouve souvent l'idée que la notion de pureté du sang a conduit les penseurs ibériques à exclure d'office les Africains de toute possibilité de revendiquer le statut de Vieux Chrétiens. Cette perspective biaisée a occulté de nombreux discours produits au cours de cette période en lien avec l'Afrique, le catholicisme et la légitimité de l'esclavage des noirs Africains. Or certains théologiens et écrivains de la période ont cherché, pour des raisons extrêmement variées, à dépeindre les Africains comme des anciens chrétiens issus de lignées à la pureté religieuse irréprochable. Le présent article analyse la manière dont Alonso de Sandoval (1576-1652), jésuite du XVII ${ }^{\mathrm{e}}$ siècle établi à Carthagène des Indes (dans l'actuelle Colombie), s'est appuyé sur des représentations de l'Éthiopie chrétienne pour construire ce type de récit des origines chrétiennes anciennes des Africains, récit dont il se servit pour justifier l'asservissement de tous les Noirs d'Afrique. Cet article retrace donc les débats pluriels et contradictoires sur l'Afrique, la couleur de peau et la chrétienté aux XVI ${ }^{\mathrm{e}}-\mathrm{XVII}{ }^{\mathrm{e}}$ siècles, en mettant en avant le besoin de réévaluer la coexistence de points de vue très différents sur la justification de l'esclavage, la couleur noire et l'Afrique dans les premiers temps de l'empire castillan.

MotS-CLÉs : esclavage, Éthiopie, Jésuites, baptême, Atlantique noir, théologie

\section{Chloe L. IRETON \\ Imagining Ethiopia in the Early Hispanic Atlantic: Slavery and Baptism in Alonso de Sandoval's Catechismo Evangelico}

Scholarship that has embraced pervasive "truths" about blackness in the sixteenth and early seventeenth-century Iberian world - primarily, that Iberians' visions of purity of blood led Iberian thinkers to exclude black Africans from the possibility of being Old Christians - has erased varied discourses pertaining to Africa, Catholicism, and debates about the legitimacy of enslaving Black Africans in this period. Such erasures or omissions have diminished contemporary understandings of the wide spectrum of plural and often contradictory contemporaneous intellectual discourses about Africa and blackness. Contemporaneous theologians and literati - for vastly different purposes - were sometimes invested in portraying black Africans as ancient Christians who possessed the purest of religious lineages. This article explores how Alonso de Sandoval (1576-1652), an early seventeenth-century fesuit based in Cartagena de Indias, drew on visions of Christian Ethiopia to construct narratives of Africans' ancient Christian origins; a history that Sandoval weaponized in order to justify the enslavement of all black Africans. The article traces plural and often contradictory debates about Africa, skin color, and Christianity in this period, while highlighting the need to re-evaluate the early Castilian empire as a site of greater coexistence of starkly different views on the justifications for slavery, blackness, and Africa.

KEYWORDS: slavery, Ethiopia, Jesuits, baptism, Black Atlantic, theology 